\title{
Registro y documentación histórica del pecio SS Colón en Acajutla, Departamento de Sonsonate. El Salvador.
}

\author{
Francisco Roberto Gallardo Mejía \\ Arqueólogo. \\ Secretaría de la Cultura de la Presidencia
}

"El progreso y la civilización de un país se obtiene por el comercio. Fenómenos de distinta naturaleza anuncian al continente americano la hora próxima de su transformación. El vapor ha comenzado a surcar nuestros mares y él despertará por todas partes el espíritu de empresa y nos sacará del letargo en que hemos permanecido"

(Gaceta Del Salvador, mayo 25 de 1849).

\section{Introducción}

El tránsito de buques a vapor en el Océano Pacífico entre 1850 y principios de 1900s fue un fenómeno histórico descomunal en América y marca la época de oro en la navegación con máquinas impulsadas con este tipo de combustión. Durante este periodo de tiempo se estableció un complejo sistema de transporte y comunicación que unió los continentes y constantemente se rompieron marcas de tiempo en viajes marinos y capacidad de carga. Este fenómeno náutico fue vital para el desarrollo industrial y económico de muchos países en el continente americano. La gran cantidad de productos que eran transportados por estos buques incluyendo añil y café generaron los ingresos para hacer posible el desarrollo de los países que contaban con puertos en el Océano Pacífico. El transporte de miles de pasajeros con diversas profesiones y especialidades o simples aventureros que buscaban una mejor vida también propició el traslado de conocimiento para el impulso tecnológico de muchas naciones americanas. El papel vital de los buques de vapor para la formación de El Salvador como nación y como país en desarrollo es un tema que amerita estudio para conocer sobre estas naves que fueron los medios de transporte y comunicación marítima más importantes durante gran parte del siglo XIX y principios del XX.

Aunque la navegación a larga distancia en el Pacífico centroamericano empieza con la presencia europea en el siglo XVI, la época de finales de 1800's 
y principios de 1900's es de especial importancia para nuestro país ya que los vapores se convierten en parte del engranaje que impulsa las economías nacionales. Tal y como ha sucedido en la evolución social de países pequeños cuyo desarrollo se debió en parte a la influencia de grandes potencias, el fenómeno de los barcos de vapor en el Pacífico centroamericano fue el resultado del desarrollo comercial de países europeos y especialmente la expansión e influencia de Estados Unidos. Al terminar Estados Unidos la guerra con México y conquistar California en 1846, la joven nación enfrenta el reto de unir este nuevo y extenso territorio con el resto del país (especialmente con el noreste). Para lograr este objetivo, el gobierno decide formar dos grandes empresas de buques a vapor: la Pacific Mail Steamship Company y The United States Mail Steamship. Estas dos empresas fueron subsidiadas por el gobierno siempre y cuando transportaran el correo estadounidense y sus vapores pudieran ser usados como buques auxiliares en caso de guerra ${ }^{1}$. La United States Mail Steamship se encargó del tránsito entre el este de Estados Unidos (Nueva York) con el Caribe Panameño (Chagres), donde los pasajeros atravesaban las 47 millas de selva tropical hasta ciudad de Panamá en el Pacifico. La Pacific Mail proporcionaba el transporte desde ciudad de Panamá a San Francisco y el territorio de Oregón con escalas en varios puertos de Centroamérica y México.

El contrato para transportar el correo entre Panamá y el territorio de California y Oregón fue otorgado a Arnold Harris de Nashville, Tennessee, una persona con mucha influencia y conexiones políticas. Sin embargo, Harris no tenía deseos de dirigir una empresa naviera, por lo que le trasladó su contrato por un buen precio a William Henry Aspinwall, uno de los empresarios más grandes en la firma Howland and Aspinwall, dedicada a la importación/exportación en Nueva York. Los vapores de Aspinwall debían estar en el Pacífico para 1848 y tocarían puertos en Centroamérica y México en su ruta a San Francisco. ${ }^{2}$

La Pacific Mail Steamship Company (que en adelante se abreviará PMSC) fue incorporada en la Legislatura de Nueva York en abril 12 de 1848 con "el propósito de construir, equipar, comprar, alquilar y poseer navíos que deben ser impulsados solamente por vapor $\mathrm{u}$ otro fluido expansivo o fuerza de locomoción, para ser impulsados para la navegación del Océano Pacifico (Escri-

\footnotetext{
1. Al respecto, James P. Delgado. To California by Sea. A Maritime History of the California Gold Rush. University of South Carolina Press. 1990.

2 Ibíd.
} 
tura de constitución de la PMSC. ${ }^{3}$. En Octubre 6 del mismo año, el California es el primer vapor que zarpa desde Nueva York al servicio en el Pacífico (Chandler y Potash, 2007). La PMSC aparece en el momento idóneo ya que el descubrimiento de oro en California en 1848 genera el deseo en decenas de miles de personas por viajar a California. Para 1851, la empresa tenía 14 vapores trabajando en el Pacifico generando grandes ganancias. ${ }^{4}$

En las décadas siguientes, La PMSC se convierte en la empresa dominante en la ruta de Panamá hasta California. A pesar de un sin número de vicisitudes que incluyeron pérdidas de navíos y competencia brutal, la empresa se mantiene firme y constante. Uno de los eventos que debilitaron a la PMSC fue el establecimiento de la ruta interoceánica por Nicaragua establecida por el magnate Cornelius Vanderbilt (1851-55). Aunque en un principio parecía que esta ruta sería la preferida, nunca sobrepasó la cantidad de personas que viajaban por Panamá. Entre 1848 y 1869, 808,769 personas viajaron por el Istmo hasta que se concluyó el ferrocarril transcontinental en Estados Unidos ${ }^{5}$ ese mismo año.

Para 1850 los vapores estaban presentes en Nicaragua y Panamá fondeando en los puertos del Pacífico. Debido a diversos factores como conflictos políticos y repetidos bloqueos por los ingleses a las costas y puertos, especialmente en el Golfo de Fonseca, la llegada de vapores a los puertos de El Salvador tomó más tiempo de lo que se esperaba en relación a los otros países centroamericanos. El primer vapor comercial que tocó los puertos salvadoreños fue El Primero. Este era un vapor de 225 toneladas de la Compañía Centroamericana de Navegación por Vapor que arribó a Acajutla el 8 de enero de 1854 e inició la carrera comercial de estos buques en el territorio (Diario Oficial de enero 13 de 1854). En febrero de ese mismo año se anunció un contrato entre el gobierno de El Salvador y el ciudadano norteamericano Thomas Wright, representante de dicha compañía.

Para 1855 Aspinwall había finalizado la construcción del ferrocarril de Panamá (Panamá Railroad), empezando en la ciudad de Colón (llamada Aspinwall por los estadounidenses) en el Atlántico y terminando en el Puerto de Panamá. Esta obra hizo que en menos de cinco años aparecieran siete distintas empresas de vapores que conectaban Nueva York, Panamá, Suramérica

\footnotetext{
3. Ibíd.

4. Op, cit.

5. Ibíd.
} 
y California. ${ }^{6}$ El ferrocarril de Panamá acortó considerablemente el tiempo que tomaba el viaje entre los dos océanos y mejoró las condiciones que aquejaban a los viajeros como los peligros de la selva, el clima tropical y enfermedades. El viaje en canoa por el río Chagres y los largos recorridos a pie o en mulas por la selva eran cosa del pasado. La cantidad de bienes y personas que llegaban a los puertos de Centroamérica, incluyendo La Libertad, Acajutla y La Unión se incrementó considerablemente gracias al ferrocarril de Panamá. Para 1856 los vapores SS Columbus de 460 toneladas y Guatemala de 1,021 toneladas tocaban los puertos salvadoreños dos veces al mes. ${ }^{7}$ El Columbus fue uno de los primeros 14 barcos adquiridos por la PMSC y actualmente es uno de los pecios registrados en la Dirección de Arqueología ${ }^{8}$

Para finales del siglo XIX el libre mercado y la exportación de productos, especialmente el café y añil hacen que el gobierno de El Salvador genere altos ingresos económicos. Estos cambios se reflejaron en la sociedad de la época, incluyendo la infraestructura, instituciones y en las estructuras sociales que se definieron marcadamente. Aunque este fenómeno de desarrollo y formación nacional es complejo y sus causas son múltiples, los vapores fueron parte del engranaje que formó El Salvador que conocemos actualmente.

Muchos buques a vapor que estuvieron en uso durante la segunda mitad del siglo XIX fueron desmantelados y otros desaparecieron en los mares, desconociendo actualmente su paradero. Todos los vapores que naufragaron y que posteriormente fueron identificados se han convertido en verdaderos sitios arqueológicos y son parte de nuestro patrimonio cultural. Cada uno de estos pecios tiene su propia historia y su influencia en las sociedades no solamente se limitó al desarrollo económico y social de El Salvador sino también de otros países latinoamericanos, europeos y de Estados Unidos. Estos pecios son los únicos sitios arqueológicos en El Salvador que han ejercido una influencia directa en la historia de otras naciones.

Actualmente, el SS Colón es un sitio arqueológico subacuático ubicado en la Playa de Acajutla, en el departamento de Sonsonate. Este es uno de los pecios

\footnotetext{
6. Al respecto, Héctor Lindo-Fuentes. La Economía de El Salvador en el Siglo XIX. Biblioteca de Historia Salvadoreña. Dirección de Publicaciones e Impresos, CONCULTURA. 2002.

7. Ibíd.

8. Al respecto, José Roberto Suárez, 1854 Barcos y Velas. Huellas Históricas Marítimas de El Salvador. Patrocinado, por el Grupo Calvo. 2011.
} 
mejor documentados históricamente y más importantes en El Salvador. Su relevancia sobrepasa las fronteras políticas pasadas y actuales ya que este vapor estuvo presente en acontecimientos internacionales trascendentes como el traslado de tropas estadounidenses hacia Filipinas durante la guerra entre Estados Unidos y España, el transporte de inmigrantes portorriqueños desde Los Angeles a Hawai, levantamientos revolucionarios, tráfico de opio, así como fue testigo en la vida y muerte de personajes importantes. El SS Colón es un verdadero sitio arqueológico que debe ser protegido e investigado para las futuras generaciones. A continuación se presenta un informe sobre el registro y documentación histórica de este pecio.

\section{Antecedentes de investigación}

A principios del año 2011 terminaba de leer el libro "1854. Barcos y Velas" escrito por mi amigo José Roberto Suárez cuando me encontré con un breve resumen sobre el SS Colón. Al final de esta interesante obra se menciona el lugar donde fue construido y las circunstancias que llevaron a que este majestuoso vapor encallara en algún lugar cerca de Acajutla en Punta Remedios, Sonsonate ${ }^{9}$. Me llamó mucho la atención este evento histórico ya que existía la posibilidad que en alguna parte de la costa sonsonateca se encontraran los restos de este buque, por lo que se podría registrar como sitio arqueológico subacuático relevante para la historia de El Salvador.

A mediados de ese mismo año pasaba un momento de ocio en la red social de Facebook donde ingresé a la página del Sr. Jorge de Sojo Figuerola. El Sr. Figuerola ha construido una sección titulada "El Salvador de Antaño" y ha subido una considerable cantidad de fotos tomadas en El Salvador durante diferentes épocas. Repentinamente me encontré con una fotografía

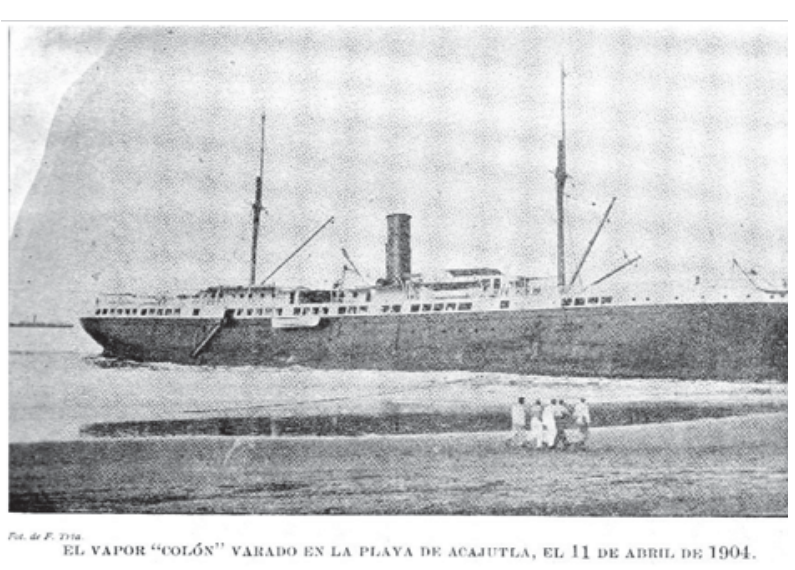

Figura 1. Fotografía del SS Colón, tomada por F. Tyla. Apareció en la revista "La Quincena" el primero de septiembre de 1904.

9. Ibíd. 
del vapor SS Colón varado en la playa de Acajutla (Figura 1). Mi sorpresa fue grande cuando observé que la foto apareció en la revista "La Quincena" el primero de septiembre de 1904, unos cinco meses después que el Capitán Irvine encalló el vapor en la playa. Cerca de esa fotografía estaba escrito que este buque se encontraba varado entre el muelle de Acajutla (actualmente solo quedan los restos) y la desembocadura del río Sensunapán.

Tomando en consideración la información conocida en ese momento, decidí realizar una visita de campo con la esperanza de encontrar los restos del buque. El día 26 de diciembre de 2011 llegué al puerto de Acajutla e hice un recorrido por la playa, iniciando en el extremo este donde se encuentran los acantilados rocosos y caminando hacia el oeste. Cuando me encontré frente a la fuerza naval, a pocos metros de donde yacen los restos del antiguo muelle (otro sitio arqueológico subacuático muy importante) logré ver a lo lejos un objeto de metal que sobresalía en la playa (Figura 2).

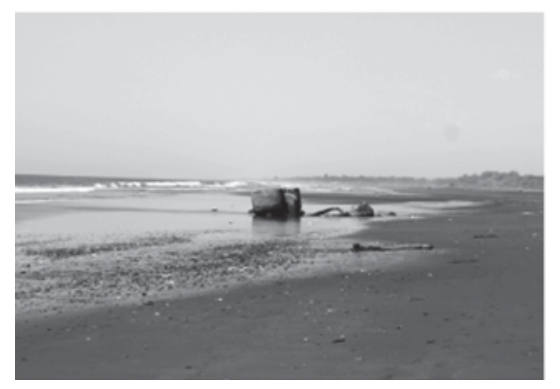

Figura 2. Restos del SS Colón en la playa de Acajutla.

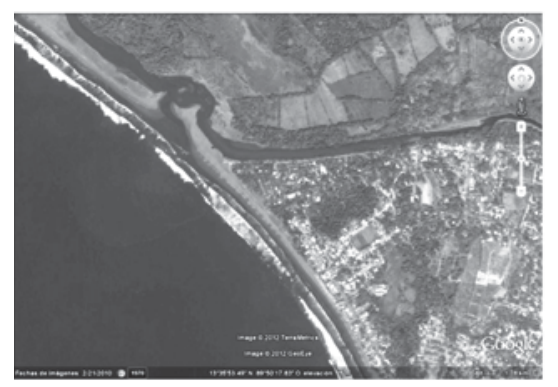

Figura 3. Vista satelital con ubicación del pecio SS Colón en círculo rojo.
Al indagar con algunas personas locales me comentaron que esos fragmentos de metal pertenecen a un barco y no sabían cuánto tiempo tienen de estar allí. El propietario de uno de los muchos negocios en la playa me dijo que en los cincuenta años de trabajar en ese lugar siempre han estado esos restos a la vista. Decidí hacer una visita más de cerca para identificar estos fragmentos de metal y después de un rápido análisis llegué a la conclusión que efectivamente pertenecen al motor de un vapor del siglo XIX, sin duda el Colón. Los restos identificados están en la playa muy cerca del oleaje (Figura 3) y son la parte superior del motor, consistente en dos cilindros donde estaban ubicados los pistones. También se puede observar un conducto que llevaba el vapor hacia los cilindros para mover los pistones. Otros fragmentos de metal que son parte del pecio pueden verse inmediatamente hacia el norte y es muy probable 
Gallardo Mejía, F.R. Registro y documentación histórica del pecio SS Colón en Acajutla, Sonsonate. El Salvador. Pág. 25-91. que gran parte del motor y otros segmentos del buque se encuentren cubiertos por la arena.

El 10 de enero de 2013 realizamos otra visita al sitio. En las ventas de la playa entrevistamos a Mercedes Portillo e Isidoro Laínez Ramírez, una pareja de avanzada edad quienes nos expresaron que los restos pertenecen a un "barco que se llamaba Colón".

\section{Ubicación}

Los restos del SS Colón se ubican en la playa de Acajutla, en el departamento de Sonsonate, a unos doscientos metros hacia el sureste de la bocana del río Sensunapan (Figura 4). Las coordenadas son: 133'52.69”N, 8950`23.10”O (Figura 3).

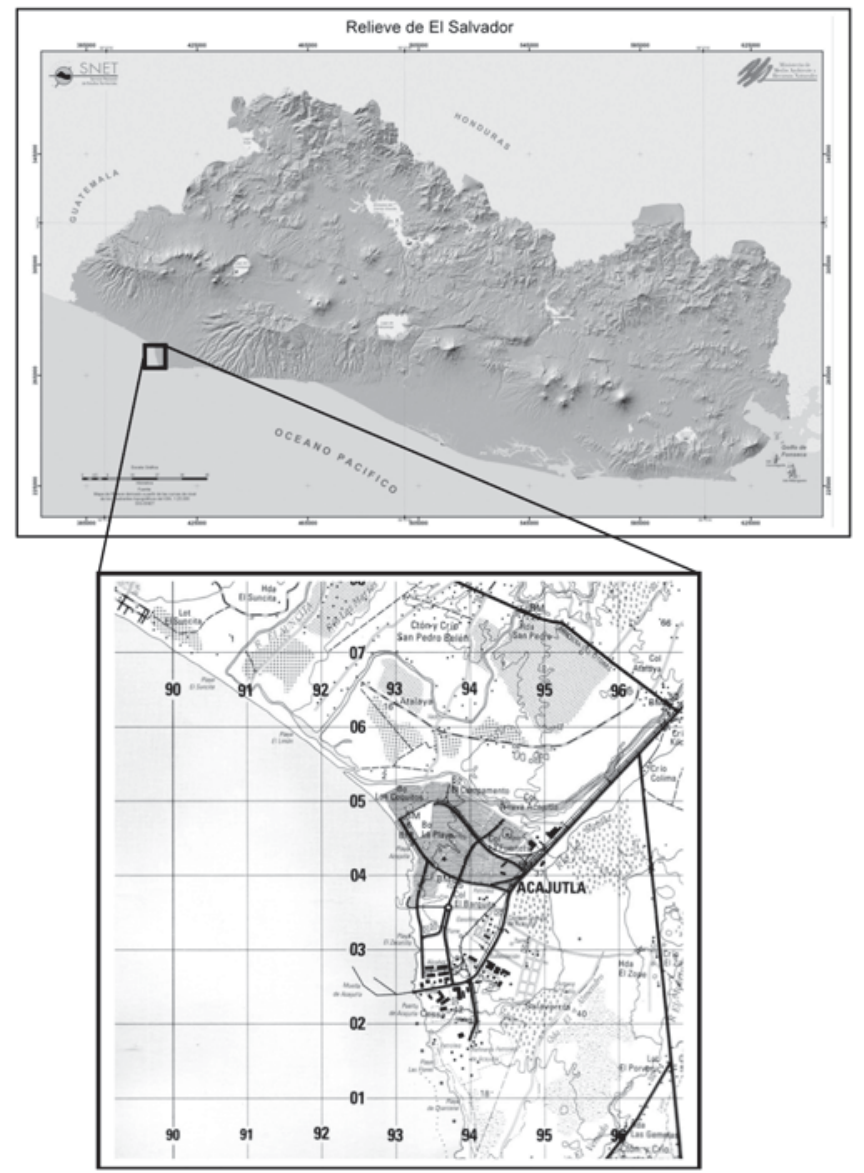

Figura 4. Ubicación del pecio SS Colón. 

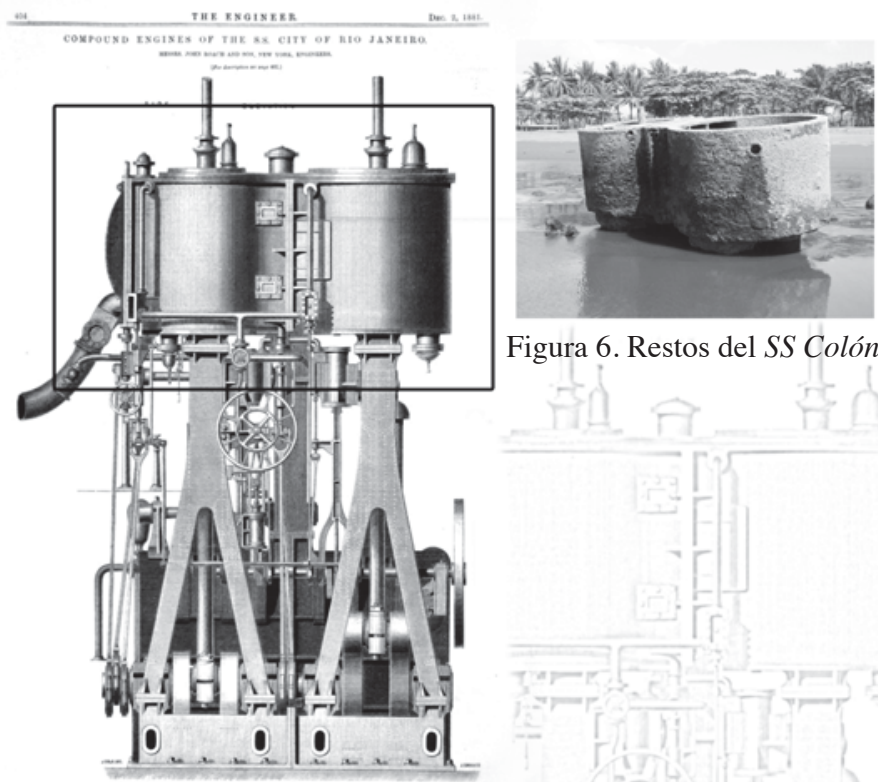

Figura 6. Restos del SS Colón.

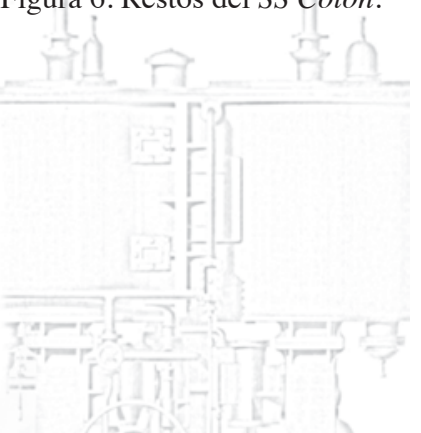

Figura 5 (izquierda). Motor del City of Rio de Janeiro, vapor construido por J Roach \& Son seis años después que el Colón. El cuadro rojo muestra los cilindros. Dibujo cortesía de Robert Schwemmer.
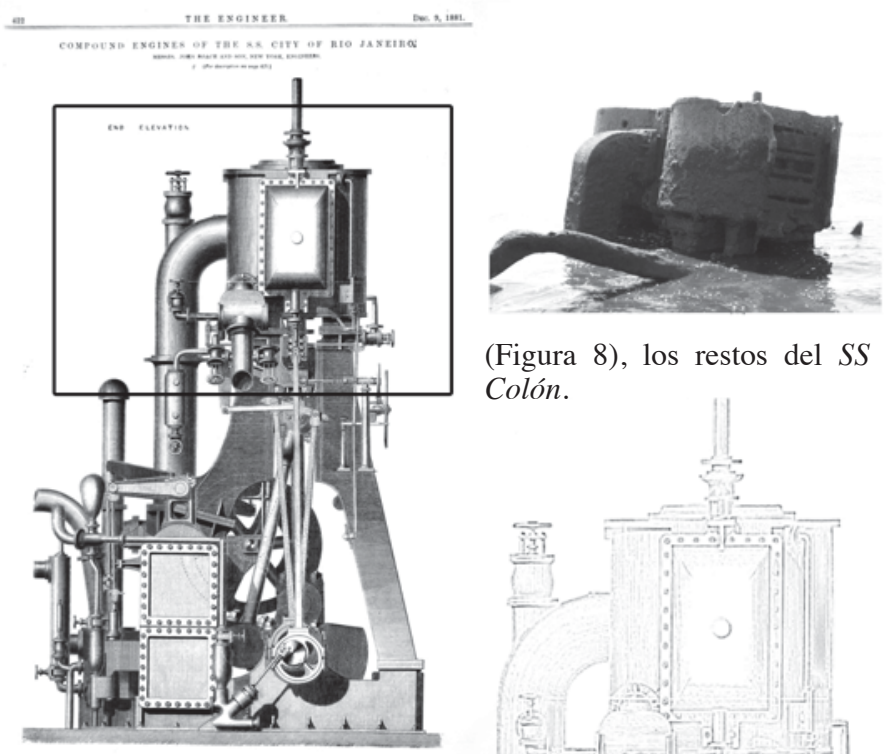

(Figura 8), los restos del SS Colón.

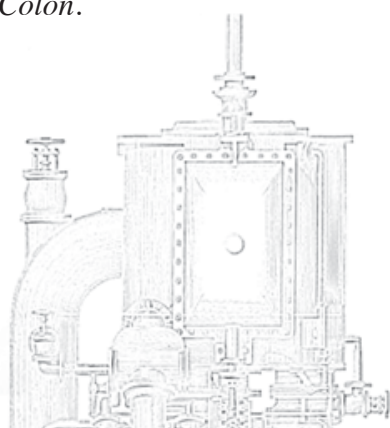

Figura 7 (izquierda). Motor del City of Rio de Janeiro. El cuadro rojo muestra los cilindros. Dibujo cortesía de Robert Schwemmer. 
Las Figuras 5 y 7 muestran dos dibujos del motor que perteneció al vapor Río de Janeiro, construido seis años después que el Colón en J. Roach \& Son, el mismo astillero donde también se construyó el Colón. Estos dibujos están marcados con un cuadro rojo para compararlos con las partes que son visibles actualmente. En las figuras 7 y 8 es evidente el conducto de hierro donde pasaba el vapor desde las calderas y llegaba hasta los dos cilindros, moviendo los pistones, uno de los cuales tenía 50 pulgadas de diámetro y el otro 88 pulgadas respectivamente. La diferencia en el diámetro de los cilindros es evidente en los restos que se identificaron en la playa (Figura 9).

\section{Historia}

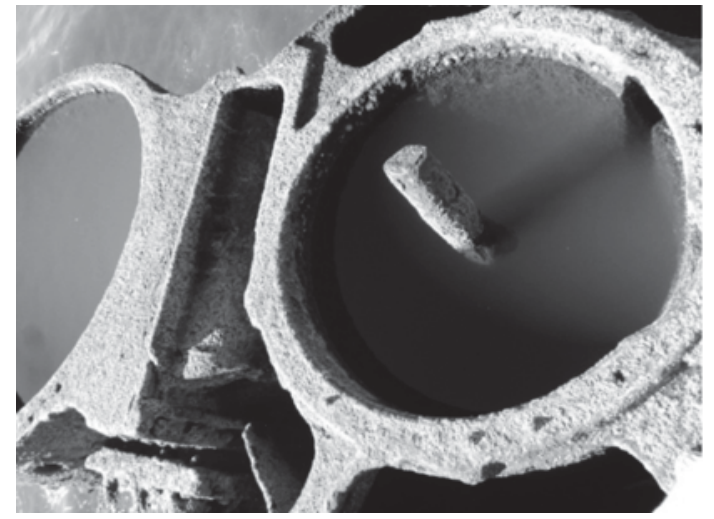

Figura 9. Cilindros del Colón en Acajutla.

\section{Construcción.}

El SS Colón fue construido en 1872 por John Roach \& Son en Chester, Pensilvania, Estados Unidos y oficialmente registrado en 1873. Este es el mismo astillero que construyó el vapor SS San Blas 10 años después, un pecio registrado en el departamento de La Libertad por la Dirección de Arqueología ${ }^{10}$ (Gallardo, 2011;2012). El Colón era de 1,843 toneladas netas y 2,686 toneladas con carga. Sus dimensiones eran 292 pies de longitud y 40 pies de eslora. Estaba equipado con un motor compuesto de dos cilindros de 50 y 88 pulgadas respectivamente con 418 caballos de fuerza (Lloyd's Register of British and Foreign Shipping). El motor fue construido por Randolph and Elder en Glasgow, Escocia y tenía cuatro calderas de 9 pies y 9 pulgadas de longitud x 13 pies de diámetro. Cada caldera estaba armada con hierro especial "para calderas" de 13-16 pulgadas con doble remache y tenían la capacidad de generar una presión de trabajo de $70 \mathrm{lbs}$ de vapor. El motor ocupaba un espacio de 13 x 19 pies y las calderas 33 pies con 8 pulgadas x 23 pies, todo 10. Al respecto, Informe Visita y Registro del Sitio Arqueológico Subacuático SS San Blas. Playa San Blas, Departamento de La Libertad, El Salvador. Documento inédito en la Dirección de Arqueología en el Museo Nacional de Antropología Dr. David J. Guzmán. 2011. También, Registro y documentación del pecio "SS San Blas". Playa San Blas, departamento de La Libertad, El Salvador. En Kóot, Revista de Museología, Museo Universitario de Antropología. Universidad Tecnológica de El Salvador, Año 2 , octubre de 2012, No. 3. San Salvador, El Salvador. 2012. 
resguardado en mamparo de hierro que se extendía desde los pisos inferiores hasta la cubierta superior, de esta forma en caso de accidente todo el sistema generador de energía se encontraba fuera del alcance de fuego o agua, "En este aspecto es el buque más perfecto a flote en nuestras aguas" (Corresponsal del New York Times, nov 18, en el Daily Evening Bulletin de San Francisco 27 de noviembre de 1872). La hélice tenía 16 pies y 3 pulgadas de diámetro. Contaba con luz eléctrica, tres cubiertas (aunque en el Daily Evening Bulletin de San Francisco de noviembre 27 de 1872 se describe con cuatro cubiertas) y fue construido para la Pacific Mail Steamship Company bajo la superintendencia del Capitán F. R. Baby (Íbid).

\section{Lanzamiento. 1872 - 1873.}

La tarde del 16 de noviembre de 1872 el Colón fue lanzado al mar desde el "Delaware River Iron Ship-Building and Engine Works", astillero que también pertenecía a John Roach \& Son. Al evento asistieron cientos de personas incluyendo el Comodoro J. R. Mullany de la Marina de Estados Unidos y el ingeniero en jefe de la Oficina de Ingeniería a Vapor en Washington. "En modelo, ella (el Colón) es muy atractiva y sus líneas demuestran que cuenta con los elementos de velocidad, estabilidad y gran capacidad de carga. Ella será equipada y sus arreglos internos serán impecables. El salón para cenas se ubicará en medio del barco y estará arreglada con estilo y elegancia no superada por otro tipo de vapor interoceánico" (Daily Evening Bulletin, noviembre 17 de 1872).

En el año que se finalizó el Colón se estaban construyendo en Filadelfia y Wilmington ocho nuevos vapores para la Pacific Mail Steamship Company. De estos, cuatro se construyeron en J. Roach \& Son. Primero se finalizó el Colón y posteriormente el Colima, un vapor "hermano" muy similar al Colón. El Colima fue otro de los vapores que fondearon los puertos salvadoreños, especialmente para el transporte de personas y café, naufragando frente a las costas de Manzanillo en México.

\section{Vida y funcionamiento en el Atlántico. 1873 - 1893.}

El 8 de enero de 1873 se anunció que el Colón (recién construido) había sido remolcado de Chester, Pensilvania hacia Nueva York por el vapor América y pronto "tomará su lugar en la Pacific Mail Line" (North American and United States Gazette, enero 7 de 1873; The Atlanta Daily Sun, enero 8 de 1873). 
En marzo de 1873 se esperaba que ambos buques transportaran la próxima cosecha de té desde China y Japón (Daily Evening Buletin, marzo 11 de 1873). Al mes siguiente se anunció en Hawai que todos estos vapores serán construidos de hierro y tendrán hélice en vez de ruedas laterales. "Dos de ellos, el Colón y el Colima ya fueron lanzados y pronto serán puestos en servicio". Es importante notar que en este mismo artículo se mencionaron algunas ventajas de los vapores con hélice sobre los de rueda lateral y la buena calidad de los motores escoceses: "El tiempo ha probado que los buques de hélice son el tipo de vapores más económicos e igual o más rápidos que los de ruedas laterales. Los motores para estos buques se construyen en Glasgow y serán introducidos gratuitamente bajo las nuevas leyes que promueven la construcción de buques americanos. Los constructores ingleses y escoceses sin duda superan a los americanos en la calidad de sus máquinas para vapores y han reducido el consumo de carbón a un punto mucho más económico. No se nos ha informado si alguno de estos buques será empleado en la ruta entre San Francisco y este puerto (Hawai), pero es posible" (Hawaiian Gazette, abril 23 de 1873).

Para mediados de 1873 el Colón ya aparece activo en el Atlántico en la ruta de Nueva York - Aspinwall (Colón), Panamá. El 10 de mayo salió de Nueva York hacia Aspinwall con varios pasajeros norteamericanos (Daily Evening Bulletin, mayo 12 de 1873).

En su regreso a Nueva York el 18 de agosto proveniente de Aspinwall, el Colón fue detenido y puesto en cuarentena por una epidemia a bordo. Los vapores que realizaban estas rutas no solamente funcionaban como transporte de pasajeros y carga, sino también traían noticias de los lugares de procedencia. En este caso los tripulantes del Colón informaron que el vapor Benicia se había perdido en el Pacífico. El Benicia salió de Mazatlán hacia Panamá el 14 de junio y no logró abastecerse de carbón en el puerto de Honduras, por lo que tuvo que continuar su viaje hacia Panamá con velas y hasta la fecha no había llegado a este puerto (Ibid, agosto 19 de 1873).

El primer arribo a Nueva York desde Aspinwall para 1874 está registrado el 4 de febrero (The Rutland daily globe, febrero 5 de 1874).

El 13 de julio de 1874 el Colón llegó a Nueva York con 125 pasajeros de primera clase y 1,260 toneladas de carga, incluyendo 480 toneladas de té (Omaha Daily Bee, julio 15 de 1874). Posteriormente el buque salió nueva- 
mente hacia Aspinwall donde llegó el 25 de julio llevando a 16 tripulantes del Guatemala. "El resto de la tripulación se encuentra bien con el capitán en el City of Guatemala" (The Daily Phoenix, julio 28 de 1874). Parece que el Guatemala sufrió un percance en la isla Walter y fue necesario trasladar a los pasajeros. Hasta el momento de escribir este informe no he encontrado datos sobre el acontecimiento sufrido por este buque.

A finales de agosto de 1876 el Colón sufrió un grave accidente. Dos días después de salir de Nueva York hacia Aspinwall (el domingo 20 a las 11:00 am) ocurrió una terrible explosión mientras se desarrollaban los servicios religiosos. Una gran fuga de vapor cubrió completamente el buque y causó alarma entre los pasajeros. Después de un tiempo se descubrió que una de las calderas había explotado (The Highland Weekly menciona que fueron dos calderas las que explotaron). El jefe de ingenieros y un bombero murieron por la explosión y los cuerpos fueron dispuestos en el mar. Varios pasajeros resultaron quemados. El buque envió señales que fueron recibidas por el vapor Etna que inmediatamente fue al auxilio y lo remolcó hasta Nueva York (The Rutland Daily Globe, agosto 28 de 1876). El Colón quedó bastante dañado debido a la explosión.

En abril 28 de 1877 aparecieron rumores afirmando que los vapores Colón, City of Tokio y City of Peking habían sido vendidos al gobierno de Rusia y que se les puso la bandera estadounidense a algunos buques rusos (Omaha Daily Bee, abril 28 de 1877). Esta noticia fue falsa ya que el Colón nunca fue vendido al gobierno ruso.

El 22 de diciembre de 1879 el Colón zarpó de Nueva York hacia Aspinwall con una delegación de oficiales de la Panama Railroad Company quienes se reunieron con Ferdinand de Lesseps (Figura 10), el reconocido ingeniero francés que había construido el Canal de Suez y tenía planificado la construcción del Canal de Panamá. En esta comisión viajaba el Sr. Trenor Parks, quien moriría unos tres años después a bordo del SS San Blas en la ruta de Nueva York a Aspinwall. En este grupo de personalidades también estaba el presidente de la Compañía de Carbón de Pensilvania y el Coronel Totten, uno de los ingenieros más antiguos de la Panamá Railroad Company y topógrafo de la línea. El Colón atracó el 30 de diciembre a las 10:00 pm a la par del vapor Lafayette, que arribó el mismo día transportando a la comitiva francesa incluyendo a De Lesseps (McCullough, 1977:106). En esos momentos el objetivo de la empresa estadounidense era construir una línea férrea adya- 
cente al futuro canal. "Si el canal es inevitable, preferimos tenerlo cerca de nuestra calle" dijo uno de los oficiales estadounidenses (The Sun, diciembre 21 de 1879). Posteriormente De Lesseps viajó en el Colón hacia Nueva York donde presentó su gran proyecto del canal interoceánico. A los reporteros que lo recibieron dentro del vapor en Nueva York, De Lesseps les dijo que el canal no costaría más de $\$ 131,720,000.00$ (McCullough, 1977:118). El intento por los franceses de construir el canal de Panamá fue uno de los fracasos económicos nacionales más grandes ocurridos en la historia de este país.

Las enfermedades tropicales, especialmente la fiebre amarilla y la malaria eran un problema serio para los viajeros de los vapores procedentes del Istmo y para los puertos donde arribaban. Los

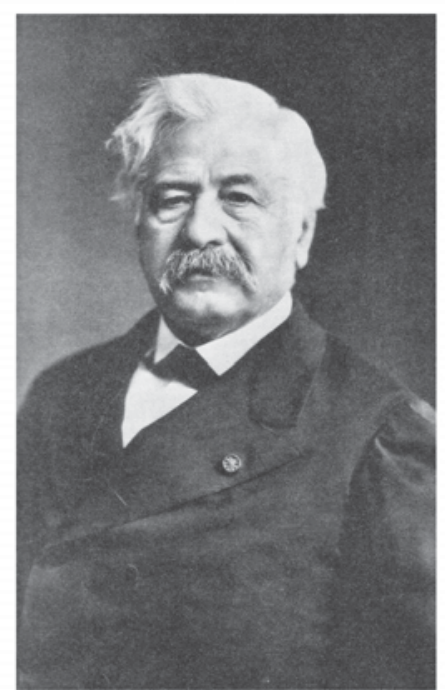

Figura 10. Ferdinand de Lesseps. Uno de los personajes más importantes que viajaron en el Colón. documentos describen numerosos casos de contagios y muertes durante los viajes, así como estrictos controles de cuarentena en los puertos de llegada. Era común que los puertos importantes contaran con un muelle de cuarentena donde los pasajeros debían pasar un control médico y los buques eran fumigados cuando se identificaba una enfermedad contagiosa a bordo. Después de los requerimientos sanitarios obligatorios, se les permitía desembarcar a los tripulantes.

El martes 15 de junio de 1880 el Colón llegó a Nueva York con pasajeros infectados de fiebre amarilla. Uno de los pasajeros murió durante el viaje cinco días después de haber zarpado de Aspinwall, por lo que se dispuso de su cuerpo en el mar. Otro pasajero contrajo la fiebre al cuarto día de salir y al llegar al puerto fue enviado al hospital donde murió esa tarde. A los sesenta pasajeros no se les permitió desembarcar sino hasta el segundo día cuando las autoridades consideraron que nadie estaba enfermo (The Sun, junio 18 de 1880).

El Colón tenía planificado una salida de Nueva York el 22 de diciembre de 1880, pero para el día 23 todavía se encontraban arreglando las máquinas ya que tuvo un desperfecto. En esta ocasión su salida fue retrasada un par de días antes de salir a Panamá (The Salt Lake Herald, diciembre 24 de 1880). 
El 17 de marzo de 1881 el Colón llegó a Nueva York con el recién electo Ministro de Chile en los Estados Unidos, Marcial Martínez y su familia (The Sun, marzo 18 de 1881).

El martes 6 de junio este buque zarpó de Nueva York hacia Aspinwall ( $\mathrm{Na}$ tional Republican, mayo 31 de 1882), posteriormente salió nuevamente el sábado 1 de julio (Ibid, julio 1 de 1882). A mediados del mismo mes regresó a Nueva York con tres hombres que se presentaron a la Oficina de Administración Pública. Uno de ellos llevaba una gran cantidad de papeles y bultos que los puso sobre un escritorio diciendo: "estas son las pertenencias de un hombre muerto." Otro de los hombres quién comprobó ser el Sr. Daniels, sobrecargo del Colón explicó que un viejo inválido llamado G, Shneider, dueño de la empresa Schneider \& Martin y propietario del Great International Hotel en Aspinwall había abordado el vapor en esa ciudad. El viejo murió al día siguiente de zarpar y sus restos fueron dispuestos en el mar. Todas sus pertenencias fueron amarradas, selladas y se llevaron a la oficina por el sobrecargo del Colón y los otros hombres (The Columbus Journal, julio 12 de 1882).

El Colón realizaba una ruta fija y continua entre Nueva York y Aspinwall en Panamá. Según los registros, el viaje de ida tomaba en promedio de 12 a 15 días, la mitad del promedio que tardaba un vapor comercial de esa época viajar entre San Francisco y Panamá. Un buen ejemplo del itinerario de este barco se presenta durante el año de 1883 del cual se tiene record de todas sus salidas cada mes del año (excepto febrero y junio). En mayo de ese año, exactamente diez años después de iniciar esta ruta, el Colón realizó el recorrido número 100.

Las salidas registradas por este buque hacia Aspinwall durante el año de 1883 son las siguientes: miércoles 10 de enero (The Sun, enero 10 de 1883), 10 de marzo de (National Republican, marzo 8 de 1883), 10 de abril (Ibíd, abril 9 de 1883).

El 4 de mayo de 1883 llegó el Colón a Nueva York después de su viaje número 100 desde Aspinwall (Sacramento daily-record unión, mayo 5 de 1883). Posteriormente sale nuevamente hacia el Istmo el 10 del mismo mes (National Republican, mayo 8 de 1883). Las salidas continuaron ese año para los días martes 10 de julio (Ibíd, julio 9 de 1883), viernes 10 de agosto (Ibíd, agosto 8 de 1883), lunes 10 de septiembre (Ibid, septiembre 10 de 1883). 
Durante la salida del 10 de septiembre de 1883 la Sra. Elizabeth C. Morton, esposa del Capitán Morton del Colón, desapareció con \$3,000.00 después que su esposo zarpó de Nueva York. El Capitán había confiado esa cantidad a su conyugue que debía pagarla en concepto de inversión en minas y debió ser transferida a nombre del Capitán ese día. Se inició una investigación y se ofreció una recompensa de $\$ 500.00$ a quien proporcionara información sobre su ubicación (Sacramento Daily record-union, septiembre 22 de 1883). La Sra. fue encontrada el 21 de septiembre en la casa de una amiga, explicando con satisfacción la razón de su ausencia y con el dinero en mano (The Sun, septiembre 22 de 1883).

Las salidas durante 1883 continuaron el miércoles 10 de octubre (National Republican, octubre 9 de 1883), sábado 10 de noviembre (Ibíd, noviembre 5 de 1883) y el 10 de diciembre, cumpliendo con más de cien viajes en diez años de trabajo conectando el Istmo con Estados Unidos.

Durante 1884 el Colón continuó con el mismo recorrido. La primera salida registrada ese año es el sábado 9 de febrero (National Republican, febrero 5 de 1884).

El jueves 2 de mayo de 1884 salió de Nueva York hacia Aspinwall (National Republican, abril 28 de 1884). En esta ocasión el capitán informó que a bordo está el propietario de una casa de citas (disorderly house) de Aspinwall y que muchas veces ha navegado de Nueva York hacia Panamá en compañía de mujeres jóvenes (de dudosa reputación). Dos detectives capturaron a Herman Luperteries, quien estaba acompañado de Annie Hirsch. Annie atestiguó que Herman le había prometido un lugar donde quedarse y una buena paga (The Sun, mayo 2 de 1884).

Continuó el registro de salidas para ese año los días sábado 31 de mayo ( $N a$ tional Republican, mayo 31 de 1884) y sábado 20 de septiembre (Ibíd, septiembre 20 de 1884).

A finales de noviembre de 1884 apareció en Nueva York un extraño reporte que causa cierta angustia a los familiares y amigos de las personas que viajaban en el vapor. El buque había salido de Nueva York hacia Panamá el jueves anterior y el reporte afirmó que se encontraban a 20 millas al sur de Cabo Hateras cuando envió señales al buque pidiendo ayuda ya que según el mensaje se encontraba en peligro. El superintendente de la PMSC afirmó que esto no 
era posible ya que el Colón no podía estar en ese lugar y que el Capitán Porter del Colón no habría dejado que pasara el State of Texas sin haber enviado un mensaje a la compañía. Los oficiales de la PMSC tenían dos teorías sobre este caso: una, que la persona que envió las señales se equivocó al mencionar al Colón como buque involucrado y la otra que fueron leídas erróneamente por el Capitán del State of Texas. Estaban seguros que el barco no era el Colón (Daily Evening Bulletin, noviembre 27 de 1884).

Para 1885, el Colón todavía realizaba recorridos en el Océano Atlántico. A finales de marzo de ese año ocurrió una revolución en Panamá y el buque fue tomado por el revolucionario Pedro Prestán, poniendo en peligro los intereses de los Estados Unidos en la ciudad de Colón. El relato de este evento apareció en uno de los periódicos:

"Parece que Estados Unidos tendrá que meter mano en el conflicto centroamericano. El lunes pasado los revolucionarios se tomaron el vapor estadounidense Colón en Aspinwall y obligaron al capitán a entregar un cargamento de armas que estaba a bordo. Ya se enviaron dos o tres de nuestras naves de la Marina para demandar reparación a estos actos" (The Iola Register, abril 3 de 1885).

Este acontecimiento fue conocido en la ciudad de Colón (Aspinwall) como "el levantamiento de Prestan", dirigido por el cartaginense Pedro Prestán, hijo de un capitán de barco inglés y madre criolla.

Todo empezó cuando Rafael Núñez fue elegido presidente de Colombia, lo que generó insurrecciones en diferentes lugares del país. La falta de tropas en la ciudad de Panamá hizo que uno de los líderes revolucionarios, Rafael Aizpuru, atacara y tomara control de la ciudad. Debido a esto las tropas gubernamentales que estaban en Colón viajaron a Panamá para atacar a Aizpuru y fue aquí cuando Prestán aprovechó para entrar en Colón. El revolucionario pasó un tiempo en esta ciudad e hizo contactos con algunos comerciantes radicados allí. Prestán odiaba a los extranjeros, especialmente a los blancos norteamericanos y también estaba en contra del presidente de Colombia Rafael Núñez, por lo que pidió un cargamento de armas desde Nueva York. La mañana del 29 de marzo el vapor Colón arribó a Aspinwall con los pertrechos de guerra. A pesar que toda la documentación estaba en regla, el Superintendente de la PMSC se negó a entregar las armas. Prestán capturó el buque, su capitán, el agente de la PMSC, John M. Dow; el Cónsul de Estados Unidos 
en Aspinwall, Robert K. Wright; el Superintendente de la Panama Railroad y dos oficiales del buque de guerra Galena, uno de los cuales fue enviado posteriormente a comunicar a su comandante naval que no se liberarían rehenes hasta que se le entregaran las armas a Prestán. Si las fuerzas estadounidenses tomaban cualquier acción, el revolucionario mataría a todos los rehenes.

El Cónsul General de los Estados Unidos en Panamá telegrafió al Secretario de Estado urgiendo que el capitán Theodore F. Kane, comandante del buque Galena, que se encontraba en el puerto, rescatara a los ciudadanos y protegiera los intereses norteamericanos. El telegrama decía "Usted fue ordenado a Aspinwall para proteger los intereses americanos y las vidas y propiedades de los ciudadanos americanos. Se espera de usted todo lo que implican estas palabras con la extensión de la fuerza bajo su mando. El Colón ha sido tomado. Devuélvalo a sus oficiales si esto está en su poder" (St. Paul Daily Globe, abril 1 de 1885).

Después de recibir el despacho, el Secretario de Estado y Secretario de la Marina ordenaron a los vapores Tennessee y Swatara hacia Key West en Florida para esperar instrucciones. Se le ordenó también al Comandante del Alliance a que procediera a Aspinwall. El Secretario de Estado le reclamó al comandante del Galena del por qué no había protegido a los ciudadanos estadounidenses y sus intereses (The Salt Lake Herald, abril 1 de 1885).

El Comandante Kane se encontró en una posición difícil ya que la presencia del Galena en el puerto era parte de una visita rutinaria en base al tratado con Colombia de 1846. El Comandante también tenía instrucciones de no intervenir en asuntos domésticos a menos que fuera una orden directa de Washington o que estuviera en peligro la propiedad de la compañía Panama Railroad. Al otro lado del Istmo, en Panamá, los buques de guerra Shenandoah y Wachusset tenían las misma instrucciones. El cónsul estadounidense ordenó al agente de la PMSC, John W. Dow a entregar las armas. Prestán se apoderó de la munición así como de un cargamento de estos pertrechos que estaba dirigido a otros países, incluyendo 250,000 cartuchos para El Salvador. Posteriormente los rehenes fueron liberados. Fue en este momento cuando Kane se acercó al Colón, amarró el buque y lo remolcó con el Galena hacia un lugar seguro dentro de la bahía.

Enojado Prestán capturó nuevamente a Dow y a Connor. Al día siguiente Kane desembarcó una fuerza de 100 hombres que, aunque contrario al deseo 
de los franceses y los americanos que tenían pertenencias en el ferrocarril, rehusó capturar a Prestán o intervenir en los sucesos. Prestán escapó internándose en la selva hacia Monkey Hill con sus rehenes, batallando contra las fuerzas gubernamentales mientras avanzaba sobre la línea férrea en medio de la selva. Durante la trifulca, Dow y Connor aprovecharon para escapar entre la maleza. Prestán se encontró en retirada regresando a la ciudad de Colón.

La mañana del 31 fuerzas del gobierno de Colombia llegaron a Colón atacando a Prestán y usando cañones en una intensa batalla. Al mismo tiempo se desató un fuego incontrolable que destruyó casi toda el área urbana de Colón (algunas fuentes afirman que Prestan incendió la ciudad cuando regresó de la selva), quedando en condición de uso solamente el muelle de la PMSC y algunos edificios en la playa. Dieciocho personas habían muerto y unas ocho mil habían quedado sin hogar" ${ }^{11}$ El levantamiento fue contrarrestado por las fuerzas de Estados Unidos, mientras Aizpuru se declaraba líder en la ciudad de Panamá. El Superintendente del ferrocarril, George Burt hizo un llamado a la marina estadounidense para que interviniera ya que las fuerzas gubernamentales habían "jugado con los switches del ferrocarril" y habían asaltado un tren. Prestán había destruido los rieles, cortado las líneas del telégrafo y descarrilado las locomotoras. En base a esta información desembarcaron fuerzas de los buques Shenandoah y Wachusset, estableciendo una precaria calma. El 10 de abril llegaron a Colón los buques Tennessee y Swatara con un batallón de Marines. Finalmente las fuerzas estadounidenses establecieron el orden. Prestán, que había escapado hacia la jungla después del incendio en Colón fue capturado y llevado a juicio. El arduo trabajo de limpieza, atender a los heridos y el esfuerzo de reconstruir Colón recayó en los oficiales de la compañía del ferrocarril (Ibíd).

El sábado 16 de mayo regresó el Colón a Nueva York con el Segundo Batallón de marinos de Estados Unidos, conocidos como los Blue Jackets (chaquetas azules) que fueron enviados para establecer la paz en el Istmo. El Teniente Wallace, al relatar la experiencia dijo que no lograron quedar bien ni con los colombianos ni con los americanos. Me enojé y le dije a un Yanki: "No vale la pena proteger este maldito pueblo ni a cualquier Yanki que viva en él... en una reunión el cónsul francés nos dijo 'invasores', cuando un ciudadano prominente se levantó y recordó el tratado que establece nuestro deber en

11. David McCollough. The Path Between the Seas. The Creation of the Panamá Canal 1870 - 1914. Simon \& Schuster Paperbacks. Rockefeller Center, 1230 Ave. of the AmericasNew York, New York 10020. 1977. 
proteger el ferrocarril, esto calmó la opinión del cónsul" (Vermont Phoenix, mayo 22 de 1885).

El revolucionario Pedro Prestán quien fue la causa de este conflicto contra el gobierno de Colombia y Estados Unidos, así como la destrucción parcial de Colón (ciudad) fue juzgado y ahorcado el 18 de agosto de ese mismo año sobre las líneas ferroviarias en Front Street frente a una de las multitudes más grandes vistas en Colón (Figura 11).

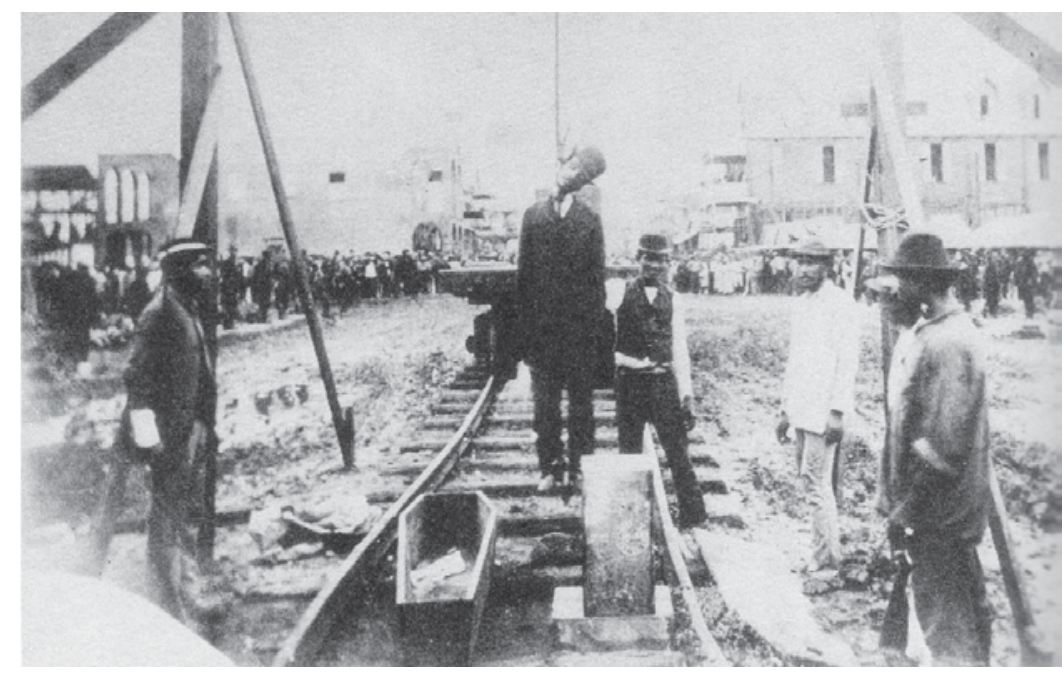

Figura 11. Ahorcamiento de Pedro Prestán, quien meses antes se había tomado el vapor Colón (Tomado de McCullough, 1977).

En junio 16 de 1885 arribaron en el Colón 124 pasajeros en primera clase, muchos de ellos latinoamericanos de alta posición económica. Algunos tenían el hábito de visitar Estados Unidos durante el verano. Los lugares preferidos eran aquellos con diversiones acuáticas como Saratoga. Entre este grupo había tres chinos-americanos (Sacramento daily record-union, junio 17 de 1885). Posteriormente zarpó nuevamente el sábado 20 del mismo mes.

El 17 de julio de 1885 apareció un anuncio en el que se comunicó que tres pasajeros de tercera clase murieron de fiebre "Chagres" a bordo del vapor durante el viaje hacia Nueva York y dos más tenían la misma enfermedad. Se determinó que esta enfermedad no era contagiosa por lo que se permitió al buque desembarcar en su muelle al arribar el miércoles 15 (Springfield globerepublic, julio 17 de 1885). 
En Agosto 20 salió de este puerto llevando correspondencia privada hacia centro y Suramérica. El correo hacia Suramérica se envió por Kingston, Jamaica (The Tombstone, agosto 26 de 1885; The Sun, agosto 21 de 1885).

En 1886, Ferdinand de Lesseps, el ingeniero francés que inició la construcción del Canal de Panamá solicitó al gobierno de Estados Unidos que designara a un representante para inspeccionar los trabajos en Panamá. John Bigelow fue designado por la Cámara de Comercio y zarpó en el Colón hacia Aspinwall el 10 de febrero. "Espero encontrarme con el Conde de Lesseps en Aspinwall. No tengo una opinión sobre el Canal de Panamá y debo ser un observador imparcial" dijo Bigelow (New York Tribune, febrero 11 de 1886).

Algunas salidas del Colón desde Nueva York hacia Aspinwall durante 1887 aparecen publicadas en el periódico The Sun. Estas son: martes 6 de febrero, (Ibíd, febrero 7 de 1887), jueves 10 de marzo (Ibíd, marzo 10 de 1887), lunes 11 de abril (IbÍd, abril 10 de 1887), sábado 14 de mayo (Ibíd, mayo 13 de 1887), sábado 11 de junio, (IbÍd, junio 9 de 1887), lunes 10 de octubre (Ibíd, octubre 10 de 1887), jueves 12 de noviembre, (Ibíd, noviembre 10 de 1887), sábado 10 de diciembre (Ibíd, diciembre 6 de 1887). Todo indica que el Colón siguió su itinerario saliendo generalmente una vez al mes exceptuando dos meses del año, posponiendo algunas salidas sin duda para reparaciones y mantenimiento.

El martes 6 de diciembre de 1887 llegó el Colón a Nueva York comandado por el Capitán Henderson con una bandera de seda que colgaba al lado del buque. Una multitud de 233 marinos y pasajeros vitoreaban sobre la cubierta. Esto se debió a que 144 marinos y 17 oficiales de la fragata Marlon regresaban a casa después de un viaje de tres años por Asia. Durante ese tiempo el Marlon circunnavegó el globo y los marinos fueron dejados en Panamá, donde posteriormente abordaron el Colón (The Evening World, diciembre 8 de 1887).

En 1888 el Colón siguió realizando viajes en la ruta Nueva York - Aspinwall. El martes 10 de enero hace el primer viaje del año hacia Aspinwall (The Sun, enero 9 de 1888), la siguiente salida es el martes 10 de febrero (Ibíd, febrero 9 de 1888) y continúa con el itinerario de salidas (estas son las encontradas en los periódicos pero probablemente eran más considerando el promedio de diez salidas por año): jueves 10 de mayo (Ibíd, mayo 6 de 1888), viernes 20 de julio (Ibíd, julio 16 de 1888), jueves 20 de septiembre (Íbid, septiembre 20 de 1888), jueves 20 de diciembre (Íbid, diciembre 19 de 1888). 
El 17 de mayo de 1888 el vapor City of Para encalló en la costa de la Isla Providencia en el Caribe. Los daños fueron considerables y tomó varios días arreglarlo. Se designó al Colón para llevar a todos los pasajeros y mercancía a Nueva York, por lo que el buque salió el 25 de mayo hacia la Isla de Providencia. "Se tiene planificado que el Colón regrese (a Nueva York) entre junio 4 ó 5" (The Evening World, mayo 24 de 1888). El City of Para fue arreglado ya que posteriormente aparece activo en los puertos salvadoreños.

A principios de febrero de 1889 el Colón llegó a Nueva York con el General John Newton, Presidente de la Panama Railroad Company en ese tiempo. Newton visitó Panamá por varias semanas inspeccionando las líneas del ferrocarril (The Evening World, febrero 14 de 1889). El miércoles 17 zarpó nuevamente hacia el Istmo.

El lunes 20 de mayo de 1889 sale el Colón de Nueva York hacia Aspinwall (The Sun, mayo 19 de 1889). El 20 de junio de 1889 el Colón llegó a Nueva York desde Aspinwall con el Dr. Cirujano D. W. Duncan, quien estaba con fiebre y fue trasladado de Brooklyn bajo una estricta cuarentena (The Daily Morning Astorian, junio 21 de 1889). El doctor fue llevado a la sección de cuarentena del hospital, supuestamente sufriendo de "fiebre amarilla genuina." La policía se quedó cuidando la casa y no se le permitía a nadie entrar o salir, incluyendo a sus tres hijas. El Doctor Boge que atendió al Dr. Duncan se encontraba indignado ya que llegó a ser un "prisionero" en esa casa. Una tal Srta. Cameron que también fue pasajera en el Colón durante ese mismo viaje murió de fiebre pocos días después de arribar a Nueva York. El barco fue extensamente fumigado (The Sun, junio 21 de 1889). Finalmente se determinó que el Dr. Duncan no tenía fiebre amarilla ya que en poco más de una semana se recuperó totalmente (Pittsburgh Dispatch, julio 26 de 1889).

El sábado 21 de diciembre de 1889 el Colón realizó la última salida de ese año hacia Aspinwall (The Sun, diciembre 17 de 1889).

En agosto de 1890 la PMSC fue demandada por $\$ 100,000.00$ por George F. Livingston quién aseguró había sufrido golpes en el Colón debido a la negligencia de sus tripulantes en septiembre del año pasado (Sacramento Daily Record Union, agosto 15 de 1890).

El 13 de agosto el Cónsul General de Guatemala en Nueva York, Jacobo Baiz recibió copia del tratado hecho entre Guatemala, Honduras, Costa Rica y Ni- 
caragua realizado el 19 de julio, formando la "Alianza Centroamericana". El tratado fue llevado a Estados Unidos en el Colón y estipulaba la remoción del General Ezeta del poder, así como el establecimiento del orden en El Salvador. Baiz dijo: "Creo que Ezeta nunca saldrá vivo del país. Será fusilado" (The Sun, agosto 14 de 1890).

En agosto 28 de 1890 el general guatemalteco Martín Barrundia fue asesinado a balazos por tropas gubernamentales en el vapor Acapulco de la PMSC mientras el barco se encontraba en el Puerto San José de Guatemala. Esto fue un acontecimiento de repercusión internacional ya que el general se transportaba en un vapor que tenía bandera estadounidense. El Congreso de Estados Unidos exigió una investigación. Según los pasajeros del que posteriormente llegaron a Nueva York (la mayoría de ellos se encontraban en el Acapulco y presenciaron la muerte de Barrundia), el asesinato sucedió porque Barrundia se resistió al arresto. “¡Nunca me llevarán con vida!” gritaba, posteriormente disparando contra las fuerzas gubernamentales. Los soldados devolvieron el fuego en defensa propia y el general cayó muerto.

Un pasajero que fue testigo del asesinato proporcionó la siguiente versión: "El vapor zarpó de San Francisco en agosto 13. Al llegar a Acapulco, México, el General Barrundia, ex - Ministro de Guerra de Guatemala, subió a bordo procedente del Starbuck, un vapor hermano. Se conocía que él era una persona hostil al gobierno actual de Guatemala y se entendía que estaba en camino hacia San Salvador. Estaba acompañado por dos hombres como guardaespaldas. Cuando el barco llegó a Champerico, Guatemala, las autoridades que habían sido prevenidas que Barrundia estaba a bordo inmediatamente mandaron dos lanchas llenas de soldados y demandaron que el general fuera entregado a ellos. El Capitán Pitts del Acapulco rehusó a su demanda. Se realizó un intento para forzarlo a entregar al General al retener los permisos de salida del barco. Pero después de haber estado detenido por veinticuatro horas el Capitán Pitts persistió en negarse a entregar a Barrundia sin una orden del Gobierno, finalmente se le permitió al barco continuar su curso.

Esto fue en agosto 27 y este mismo día el vapor llegó a Puerto San José. Recién anclado el buque se enviaron desde tierra dos lanchas con soldados para mantener estrecha vigilancia y que nadie sin credenciales se bajara del barco para ir a la costa. A una distancia de un tiro de pistola del lugar donde estaba el Acapulco había dos barcos de guerra de los Estados Unidos. El Capitán 
Pitts había telegrafiado desde Champerico al oficial al mando de estos barcos solicitando asistencia, pero su mensaje no fue enviado. Ahora les hizo una solicitud personal de ayuda. La respuesta fue que los hombres de guerra no podían actuar sin una orden del capitán del puerto.

Al día siguiente el barco fue invadido nuevamente por comandantes de una fuerza especial de hombres acompañados por otra lancha llena de soldados. Esta vez los oficiales guatemaltecos llegaron con una 'orden de arresto' girada por el Ministro Americano Lansig B. Mizner. Después de ser presentado al Capitán Pitts, el comandante guatemalteco mostró sus documentos e hizo una demanda formal para la entrega del General Barrundia. Después, el comandante dio instrucciones para que todos los pasajeros de primera clase fueran trasladados bajo cubierta. Cuando esta orden había sido girada, los oficiales guatemaltecos acompañados por el Capitán Pitts procedieron a la habitación del General Barrundia.

Justo cuando llegaron a la habitación, el Capitán Pitts trató de convencer al General de entregarse y empezó a leer la orden de arresto. El General Barrundia los había encontrado calladamente frente a la puerta, pero al constatar que no se podía hacer algo al respecto entró a la habitación por sus revólveres y exclamando: 'muy bien', disparó. La bala pasó a la par de la cabeza del Capitán Pitts, quien, junto con el comandante guatemalteco corrió hacia su habitación, cerró la puerta con llave y se escondió debajo de la cama, dejando la cacería humana a los oficiales especiales. Barrundia tenía vista muy corta, y estando nervioso no le fue posible dañar a nadie aunque los persiguió dentro y fuera del salón disparando salvajemente. Finalmente los oficiales le dispararon desde varios puntos sobre la cubierta 'de huracanes' y Barrundia fue abatido. El "valiente" comandante salió de su escondite, caminó hacia el hombre muerto y le pegó un tiro en el cráneo.

El cuerpo fue enrollado en un pedazo de lona para vela y se pidió ayuda al otro bote ya que el general era una persona muy pesada. El bulto fue rodado hacia abajo sobre la tarima y después a uno de los botes. Después lo trasladaron a la orilla desde donde fue enviado a Guatemala y enterrado al día siguiente...no se le autorizó al barco continuar su camino hasta que el equipaje de Barrundia fue registrado. Los americanos a bordo estaban llenos de indignación y pena por todo el evento." (The Globe-republican, septiembre 17 de 1890). 
N. Mizner, hijo del reconocido ministro estadounidense Lansig B. Mizner, quien giró la orden de captura contra Barrundia fue testigo del asesinato, él y todos los testigos llegaron a Nueva York el 12 de septiembre en el Colón para dar declaraciones (The Daily Morning Astorian, septiembre 14 de 1890).

A mediados de septiembre de 1890 los empleados de la Panamá Railroad Company iniciaron una huelga en Colón, Panamá. El 15 de septiembre se enviaron trabajadores para descargar el Colón ya que se encontraba en el puerto, pero al llegar los trabajadores en el tren fueron recibidos por unos 500 huelguistas y simpatizantes quienes atacaron los carros y evitaron que el buque fuera descargado. Debido a esto, el trabajo tuvo que ser suspendido temporalmente. La huelga terminó cuando se decidió pagar $\$ 1.25$ y $\$ 1.50$ por día a los trabajadores (Sacramento Daily Record Union, septiembre 15 de 1890).

El sábado 20 de diciembre de 1890 salió de Nueva York hacia Aspinwall, realizando el último viaje de ese año (The Sun, diciembre 18 de 1890).

A principios de febrero de 1891 el Colón pasó por una racha de peligros que casi lo hunden. Se enfrentó a una tormenta fuertísima en su trayecto desde Nueva York hacia Panamá, específicamente en la corriente del Golfo de México. Las olas eran muy grandes y pasaban sobre la cubierta, entrando en las habitaciones y asustando a los pasajeros. El cuarto del capitán fue azotado por una ola que arrancó la puerta. El mar estaba tan fuerte y las olas tan altas que los oficiales no podían mantener su puesto en el puente. Los pasajeros tuvieron que pasar bajo cubierta más de 48 horas. Al día siguiente apareció una luz justo frente al trayecto del Colón (otro buque). Por un momento no se sabía si ocurriría un choque de vapores, pero la catástrofe se evitó pasando a pocos metros de distancia entre ellos. En esos momentos el Colón era dirigido por el Capitán Lima (The Salt Lake Herald, febrero 4 de 1891). El Capitán Lima no aparece en documentos posteriores al mando de este vapor.

El viernes 20 de febrero de ese mismo año el Colón salió de Nueva York hacia Aspinwall (The Sun, febrero 16 de 1891) y posteriormente el lunes 20 de abril (The Sun, abril 20 de 1891).

El 14 de mayo de 1891 el Colón arribó a Nueva York con el pasajero Edward Eyre. El Sr. Eyre es el representante de una empresa en Callao, Perú, que pertenece a su tío William R. Grace. El gobierno de Perú le ha entregado 
"todas las líneas de ferrocarril que se han construido en Perú" para cancelar la deuda externa. En esos momentos ocurría una revolución en Chile por lo que el Presidente Balmaceda mandó hacer billetes a Nueva York para financiar su lucha contra los revolucionarios. El 27 de junio de 1891 el Colón salió de Nueva York con $\$ 3,000.000$ en billetes mandados hacer por Balmaceda a la American Bank Note Company. El Presidente mandó a fabricar $\$ 12,000,000.00$, pero el resto será enviado en otro vapor (The Anaconda Standard, junio 28 de 1891).

El sábado 20 de junio de 1891 el Colón salió de Nueva York hacia Aspinwall (The Sun, junio 20 de 1891) y posteriormente el jueves 1 de octubre (Ibíd, septiembre 27 de 1891).

El 26 de octubre de 1891 el Colón llegó a Nueva York después de tener graves desperfectos mecánicos. Justo cuando pasaba frente a Cabo Hateras el jueves 22, atravesó una fuerte tormenta. La parte frontal del cardán cerca de la hélice se quebró a mediodía. El repentino paro de las máquinas causó alarma a sus sesenta y seis pasajeros. El Capitán Hender y sus oficiales restauraron la calma asegurándoles que el buque estaba fuera de peligro. Cuando ocurrió el accidente el viento había cesado y el mar estaba más calmado. Se izó suficiente vela para que el buque avanzara hasta que la quebradura en el cardán fuese reparada. El arreglo tomó 24 horas y se logró por el uso de abrazaderas y tenazas que se llevaban específicamente para este tipo de accidentes. El vapor prosiguió a una velocidad más lenta y los pasajeros felicitaron al capitán y al Jefe de Ingenieros por su capacidad y tenacidad (The Sun, octubre 27 de 1891).

Para muchas personas los viajes en vapor eran una experiencia única en la vida. Para otras era común transportarse en estas máquinas ya fuese por negocios o placer. Aunque el trayecto entre Aspinwall y Nueva York no era muy largo comparado al cruce transatlántico o al viaje entre Panamá y San Francisco, la mayoría de travesías se sentían largas y podían ser aburridas. Estos viajes se convertían en oportunidades para conocer personas y compartir historias mientras se surcaba el mar, ya fuese en el salón durante la cena o en cubierta bajo una noche estrellada. Claro, esto cuando las condiciones naturales eran favorables y el mar permitía estas actividades ya que en momentos de tormenta se pasaban angustias y muchas veces solo se pensaba en sobrevivir. Había diferentes formas de pasar el tiempo durante los viajes, como juegos en la cubierta, naipes y bebida, pero sin duda la actividad principal era compartir 
historias con otros pasajeros y en muchos casos con el capitán. En diciembre 5 de 1891 apareció un artículo ameno titulado “¿Un Bebé o un Tigre?” Esta narración inicia con una conversación cuando el Colón tenía 24 horas de salir de Aspinwall hacia Nueva York. Eran las once de la noche y no se veía ni una arruga sobre el mar. El Colón parecía atravesar un lago tirando un espray de agua fosforescente a los lados con una velocidad de catorce nudos por hora. Era la noche perfecta para que tres pasajeros y el capitán iniciaran una plática observando el mar. Uno de los pasajeros, el Cónsul Americano que regresaba a su hogar le preguntó al Capitán Paul (no encontré otro registro de este capitán en el Colón) si tenía alguna historia qué compartir. El Capitán narró que hace algún tiempo vivía cerca de Guayaquil ya que había sido enviado a ese país para recuperar un vapor que había naufragado en el rio Guayaquil. Su casa estaba en medio de la selva lejos de cualquier poblado, por lo que era conveniente mantener la puerta de la casa cerrada para que no entraran animales salvajes mientras trabajaba en el puerto.

Una vez el capitán regresó del trabajo a media noche y encontró la puerta principal abierta, pero no le dio importancia. Al entrar a su cuarto vio un bulto en la cama y pensó que su esposa había dejado a su hijo pequeño "Buster" en la cama. El capitán se acostó como a la una de la mañana cuando repentinamente sintió una pata peluda con garras sobre su estómago. Debido a que estaba demasiado oscuro y recién se había mudado a esta casa, no se acordaba dónde estaba la salida del cuarto, por lo que decidió esperar ansiosamente hasta el amanecer para salir corriendo. Cuando los primeros rayos solares entraron al cuarto logró divisar la puerta. Rápidamente saltó y al salir cerró la puerta dejando la bestia adentro. Sin pensarlo y en pijamas agarró su rifle y con una escalera colocada en la parte exterior de la casa subió hasta la ventana del cuarto. El capitán vio un par de ojos que reflejaban adentro de la habitación a los que disparó un par de veces, oyéndose al animal caer sobre el piso de madera. El Capitán no quiso contarle a sus amigos el final de la historia y amablemente los citó a su cabina al día siguiente para que su esposa les terminara de narrar lo sucedido esa noche.

$\mathrm{Al}$ día siguiente los cuatro personajes se encontraban parados a la par de un baúl en la cabina del capitán. La Sra. Paul sacó una piel y la extendió en la cubierta. "Pobre viejo Jumbo" exclamó. "El Capitán Paul tuvo que pagar $\$ 200.00$ por matar el buen perro Newfoundland del Sr. García nuestro vecino, así que nos quedamos con la piel (The Wichita Daily Eagle, diciembre 5 de 1891). 
En 1892 el Oficial en Jefe del Colón era el Sr. Trask quien empezó a trabajar en la PMSC en 1890. Posteriormente, esta persona fue transferida como Oficial en Jefe del City of Peking, que para 1897 era el vapor más grande de la PMSC (The Hawaiian Gazette, diciembre 24 de 1897).

\section{El Colón en el Pacifico. 1893 - 1904.}

A mediados de 1893 el Colón ya aparece en el Pacifico realizando la ruta San Francisco/Panamá. La primera referencia de este buque en las costas salvadoreñas es su llegada a Acajutla el 12 de junio de 1893 procedente de San Francisco. En esta ocasión no trajo carga, solamente siete pasajeros y cuatro sacos de correspondencia. Al día siguiente a las 7:00 am fondeó en La Libertad con 4,793 bultos, dos pasajeros y seis sacos de correspondencia (Diario Oficial, martes 13 de junio de 1893).

El 11 de julio de 1893 ocurrió una trifulca a bordo: dos oficiales atacaron al Primer Oficial, J. G. Dorris. Al principio uno de los oficiales tuvo un altercado con Dorris y le pegó con un revólver sin balas, después el otro oficial entró al pleito contra Dorris. Los dos hombres fueron encarcelados por asalto con arma mortal al llegar a San Francisco (The Hawaiian Gazette, julio 25 de 1893), uno de ellos fue absuelto pocos días después.

A finales de agosto de 1893, se anunció que el puesto de capitán en el Colón estaba vacante debido a la muerte del Capitán Avery (The Morning Call, agosto 31 de 1893).

En diciembre de 1893 se anunció en el Diario Oficial de El Salvador la llegada de la North American Navigation Company. Una empresa que ofrecía mejores precios que la PMSC con los vapores Saturn, Keweenah, Progreso y Saint Pard. Se anunció la próxima llegada del Saturn a Acajutla el 11 de diciembre y se calculó que el Progreso llegaría el 20 (Diario Oficial, sábado 6 de enero de 1894). Para enero de 1894 ambos vapores ya fondeaban en Acajutla (Diario Oficial, lunes 29 de enero de 1894).

Durante 1894 el Colón continuó sus visitas a los puertos salvadoreños. El primer arribo durante ese año es el 5 de febrero de 1894 fondeando en Acajutla procedente de San Francisco con 8,052 bultos y varios pasajeros (Diario Oficial, martes 6 de febrero de 1894). 
En marzo de 1894 los tripulantes del Colón llegaron a San Francisco con la noticia que los ecuatorianos se están armando y enviando tropas a la frontera con Perú, que parece no hacer mucho para contrarrestar un ataque (The Morning Call, marzo 17 de 1894). Este mismo mes fue creado un nuevo distrito de inspectores dirigido por el Inspector Greenan quien ha sido promovido a este puesto. Como inicio en su trabajo el Inspector decomisó cuarenta latas de opio encontradas a bordo del vapor Colón. Esto sumó un total de ciento veinte latas que fueron decomisadas en este buque (Ibíd). Parece que el Colón fue involucrado en el tráfico de opio procedente del Oriente vía Panamá.

En octubre 2 de 1894 el Colón llevó noticias a San Francisco sobre la muerte del historiador salvadoreño Silveiro A. Luis. El hombre de letras recién había terminado un documento sobre historia y geografía de El Salvador, donde se criticaba a los Ezeta y sus amigos, por lo que tenía planificado viajar en el Colón para publicar su obra en San Francisco. La mañana antes que saliera el Colón del puerto salvadoreño, Silveiro fue encontrado en una calle de San Salvador muerto con un puñal incrustado en su corazón. El manuscrito desapareció (New York Tribune, octubre 30 de 1894).

El primer registro del Colón en costas salvadoreñas durante 1895 es cuando fondea en Acajutla el 8 de enero procedente de San Francisco. Trajo cuatro sacos y tres paquetes de correspondencia, 5,293 bultos de mercaderías y varios pasajeros (Diario Oficial, 8 de enero de 1895).

A principios de junio de 1895 el Colón transportó a Panamá varias personas que sobrevivieron al naufragio del Colima que se hundió frente a Manzanillo, México el 27 de mayo. Este era el buque "hermano" del Colón que también visitaba frecuentemente los puertos salvadoreños. Su hundimiento se debió principalmente a una fuerte tormenta que empezó el día anterior pero arreció la mañana del 27. Sin embargo, en esta ocasión algunos sobrevivientes atestiguaron en Nueva York que la carga consistente principalmente de madera, estaba desordenada y mal asegurada en la cubierta, lo que cambió el nivel de flotación del barco y facilitó el hundimiento. (TSFC, junio 13 de 1895). Algunos parientes de las personas que murieron demandaron a la PMSC basados en que la carga estaba mal asegurada.

El 14 de agosto de 1895 el Sr. Ricardo H. Von Winckler quien dirigía la construcción del nuevo ferrocarril de C. P. Huntington en Guatemala llegó en el Colón a San Francisco. Winckler dijo que la empresa estaba invirtiendo 
una cantidad de dinero muy grande para la nueva línea férrea y que las tierras estaban subiendo de precio rápidamente ya que pasa por el corazón de las fincas cafetaleras y cañeras de Guatemala (The North Platte semi weekly tribune, agosto 16 de 1895). En ese mismo arribo venía uno de los tripulantes que viajaban en el Colima cuando naufragó frente a las costas en Manzanillo, México. El Sr. J. E. Chilberg traía un pequeño reloj de oro que pertenecía a su esposa y marcaba las 11:20, la hora trágica del hundimiento del Colima debido a una tormenta. Chilberg cayó al agua con algunos pedazos de madera de cubierta (uno de ellos le pegó al reloj) y quedó flotando en el agua con otros pasajeros. Observaron el vapor San Juan que se encontraba a unas 3 millas de distancia y posteriormente les pasó muy cerca sin verlos. Las señales y gritos de los sobrevivientes no fueron oídos por la tripulación del San Juan. Treinta y tres horas después llegaron a la costa y fueron rescatados por los nativos (TSFC, agosto 15 de 1895).

El primer arribo del Colón a puerto salvadoreño en 1896 fue en enero $30 \mathrm{cu}-$ ando fondeó en Acajutla procedente de San Francisco. Llegó con 2,495 bultos de mercadería, 11 sacos, 4 piezas de correspondencia y varios pasajeros (Diario Oficial, enero 30 de 1896).

El 4 de julio de 1896 el Colón llegó a San Francisco después de 21 días de trayecto desde Panamá, anclando en el muelle de la calle Powell. Capitaneado por McKinnon, trae "treinta y cuatro blancos en primera clase, también treinta chinos en ruta a Hong Kong" (TSFC, julio 5 de 1896).

A principios de septiembre se asignó a Mcgrane Coxe de Nueva York como el nuevo Ministro de Estados Unidos en las repúblicas de Honduras y Guatemala. El 7 de septiembre de 1896 el Sr. Coxe se encontraba esperando que el Colón saliera hacia Centroamérica y ejerciera su nueva posición. El Sr. Coxe era graduado de Yale y perteneció al Club de Drama y al Club Tuxedo (TSFC, septiembre 7 de 1896).

En noviembre de 1896 se anunció que se realizaría un campeonato mundial de billar en San Francisco. Para este evento se trajo al campeón mundial desde Francia. Sin embargo, no se contaba con una mesa de billar apropiada para jugar el llamado "champion game," un estilo de juego clásico para el que se necesita una mesa especial. Debido a esto se mandó a traer una mesa con medidas estándar desde el Este de Estados Unidos. En ese momento la mesa ya se encontraba viajando en el Colón desde Panamá hacia Acapulco. 
El Sr. Mazzoli, campeón de billar del sur dijo: "Extraño, ¿no es así? En toda esta costa no hay una sola mesa de billar moderna hecha a medida estándar, excepto la única que sale mañana en el vapor Colón hacia Acapulco" (TSFC, noviembre 4 de 1896).

En marzo de 1897 se anunció que un niño murió a bordo del Colón. Se llegó a la conclusión que la causa de muerte no fue fiebre amarilla, por lo que se llegó a la convicción que no habían motivos para temer el contagio de esta enfermedad cuando llegara el buque a San Francisco (TSFC, mayo 26 de 1897). En abril de 1897 el buque todavía es dirigido por el Capitán Geo Mckinnon y el 21 del mismo mes llegó nuevamente a Acajutla procedente de San Francisco. Trajo a este puerto 79 marineros y descarga 2,451 bultos de mercaderías, 24 sacos de correspondencia y 6 paquetes, así como varios pasajeros (Diario Oficial, miércoles 21 de abril de 1897). Dos días después (23 de abril) fondeó en La Libertad donde deja 2,238 bultos de mercadería (Diario Oficial, viernes 23 de abril de 1897).

El 7 de mayo llegó nuevamente a El Salvador en su regreso de Panamá, fondeando a las 6:00 am en La Libertad. Descargó 347 bultos de mercaderías, 61 sacos de correspondencia y a los pasajeros A. E. Corbruy, A. L Egliso y J. Unnela (Diario Oficial del 7 de mayo de 1897). Al día siguiente llegó a Acajutla. Posteriormente continuó hasta San Francisco donde llegó el día 25 con la bandera amarilla que significaba una enfermedad contagiosa a bordo. Inmediatamente fue ordenado a cuarentena. Justo después que el vapor salió de Panamá se desataron varios casos de "una fiebre maligna" que empezaron en tercera clase y terminaron con la vida de tres tripulantes.

En septiembre 19 de 1897 el Colón transportó a San Francisco dos personajes importantes de la historia de Guatemala. En ese momento Próspero Morales lideraba una revolución en ese país para derrocar al General José María Reina Barrios. Los dos tripulantes llegaron a San Francisco con el objetivo de esperar los resultados de la revolución. Uno de estos "refugiados diplomáticos" era Manuel Morales Tobal, en ese momento Ministro de Agricultura y primo de Próspero Morales, el líder revolucionario que luchaba contra el gobierno en el poder. "Dice que ha dejado su puesto en el Ministerio con un permiso otorgado (por el gobierno) porque según él estaba enfermo. Su actual situación es muy peculiar. Pero está determinado a permanecer neutral hasta definir quien toma control de la República, si su querido amigo personal el Presidente Barrios o su estimado primo, el revolucionario Morales" (TSFC, septiembre 20 de 1897). 
El otro refugiado era Francisco Toledo, abogado, diputado depuesto, prisionero político liberado y revolucionario. Creyó conveniente dejar el país ya que no se había definido un vencedor. Sin embargo, para estas fechas Próspero Morales ya había tomado gran parte del control al mando de las fuerzas revolucionarias, incluyendo las comandancias militares (Ibíd). Un año después, en agosto de 1898, Morales es capturado con ayuda de fuerzas inglesas que fueron transportadas en el buque de guerra Leander y comandadas por el Capitán Fegan. Fue necesario solicitar la ayuda de la fuerza naval inglesa ya que en ese momento Estados Unidos tenía destacados todos los buques de guerra en otros lugares para combatir las fuerzas españolas (The New York Times, agosto 20 de 1898).

El relato de los acontecimientos fue tomado a los tripulantes en entrevistas separadas que se realizaron en sus habitaciones del "Occidental Hotel" el día 17 de septiembre de 1897.

En noviembre 26 de 1897 el Sr. Charles Olsen inició una demanda por $\$ 20,000.00$ contra la PMSC. Esta disputa legal empezó cuando una paca de algodón cayó sobre Olsen y le rompió la pierna derecha mientras viajaba de Guatemala a San Francisco. Olsen reclamó que el accidente ocurrió debido a que las pacas habían sido mal colocadas por los empleados de la empresa (TSFC, noviembre 27 de 1897).

En marzo 23 de 1898 el Colón llegó a San Francisco desde Panamá con Claudio Urrutia y Manuel Amesquita, ingenieros civiles que trabajaban para el gobierno de Guatemala para delimitar la frontera entre México y este país. Tres años antes ambos países estuvieron involucrados en una seria disputa debido a la línea fronteriza. En esta ocasión Guatemala perdió grandes extensiones de terreno (Omaha Daily Bee, marzo 24 de 1898).

En 1898 empezó la guerra entre España y Estados Unidos, conocida por los estadounidenses como la Guerra Hispanoamericana (Spanish-American War). Este conflicto inicia principalmente por el involucramiento de Estados Unidos en la independencia cubana y ataques americanos en las posesiones españolas en el Pacífico, siendo parte del resultado de la expansión estadounidense de la época. Una de las causas que detonaron la Guerra Hispano-Americana y el involucramiento de Estados Unidos en Cuba fue la explosión que hundió el vapor Maine en la Bahía de la Habana el 15 de febrero de 1898. Algunos medios escritos y el público norteamericano en general culparon de inmediato 
a los españoles. El inicio de esta guerra obligó a Estados Unidos a usar los buques de diferentes compañías, entre ellas la Pacific Mail Steamship Company para trasladar numerosas tropas a los campos de batalla, incluyendo el traslado de las famosas “Tropas de Manila” desde San Francisco a Filipinas. En mayo de 1898, en plena guerra, el Colón y The China fueron contratados por el Secretario Asistente del Departamento de Guerra, Melklejohn para una segunda expedición con el objetivo de trasladar tropas de San Francisco a Filipinas. Esto se logró cuando el Secretario estableció un acuerdo con C. P. Huntington quien en ese momento era el Presidente de la PMSC. Cuando estos buques fueron contratados, el Colón se encontraba en San Francisco cargando mercaderías para transportarlas al Oriente y se esperaba que zarpara el 28 de mayo. The China había llegado a San Francisco el día anterior. Con la incorporación del Colón, que fue contratado por \$22,500.00 y The China, ya se tenían cinco buques para esta expedición. Aunque los Estados Unidos sabía que España no tenía la capacidad de atacar estos barcos durante el trayecto, el convoy fue recibido por una escolta naval al acercarse a las Filipinas. Ambos buques (Colón y The China) llevaron 2,500 hombres y fueron parte de la segunda expedición formada por los cinco buques para transportar tropas hacia las Filipinas (Figura 10) que en total lograron el transporte de aproximadamente 5000 soldados. Los navíos que formaron parte en este transporte de tropas fueron: el Centennial, Zealandia, Ohio, Colón y The China. Su salida estaba planificada para el 8 de junio pero sufrió retraso de siete días.

En junio 15, el Colón finalmente fue abordado en San Francisco por tropas voluntarias del estado de Utah que habían acampado por un mes en California. Este evento aparece en un artículo del periódico Salt Lake Herald titulado "Los jóvenes de Utah a Flote. Las Lujosas Habitaciones del Colón para la Batería A. Viajando Como Ricos".

Después de un mes de espera en un campamento ubicado en las dunas de arena en California, un grupo de ansiosos soldados originarios de Utah abordan el Colón para su viaje hacia las Filipinas. Su entusiasmo por ver batalla era grande y en su camino hacia el muelle se podía ver las casas decoradas con flores y la fotografía del Almirante Dewey en las ventanas. En este trayecto hacia los muelles también estaban incorporados soldados originarios de Pensilvania y Colorado. "Ninguno de ellos está enfermo, pero hay un secreto que explica su buena salud. Ellos aborrecen la enfermedad más que el Indio. Enfermarse es considerado acobardado y "de mujeres"' (The Salt Lake Herald, junio 18 de 
1898). El Colón sale de San Francisco acompañado de otros vapores que eran dirigidos por el buque The China (Figura 12).

La artillería era considerada la rama más alta de la milicia, por lo que la Batería A fue asignada a las cabinas de primera clase, las mismas donde se encuentran los oficiales y están equipadas de forma lujosa. El resto de las tropas fueron menos afortunadas ya que sus habitaciones son muy diferentes y cuentan con camarotes donde hasta dos soldados comparten una cama. Hubo muchas quejas por la comida.

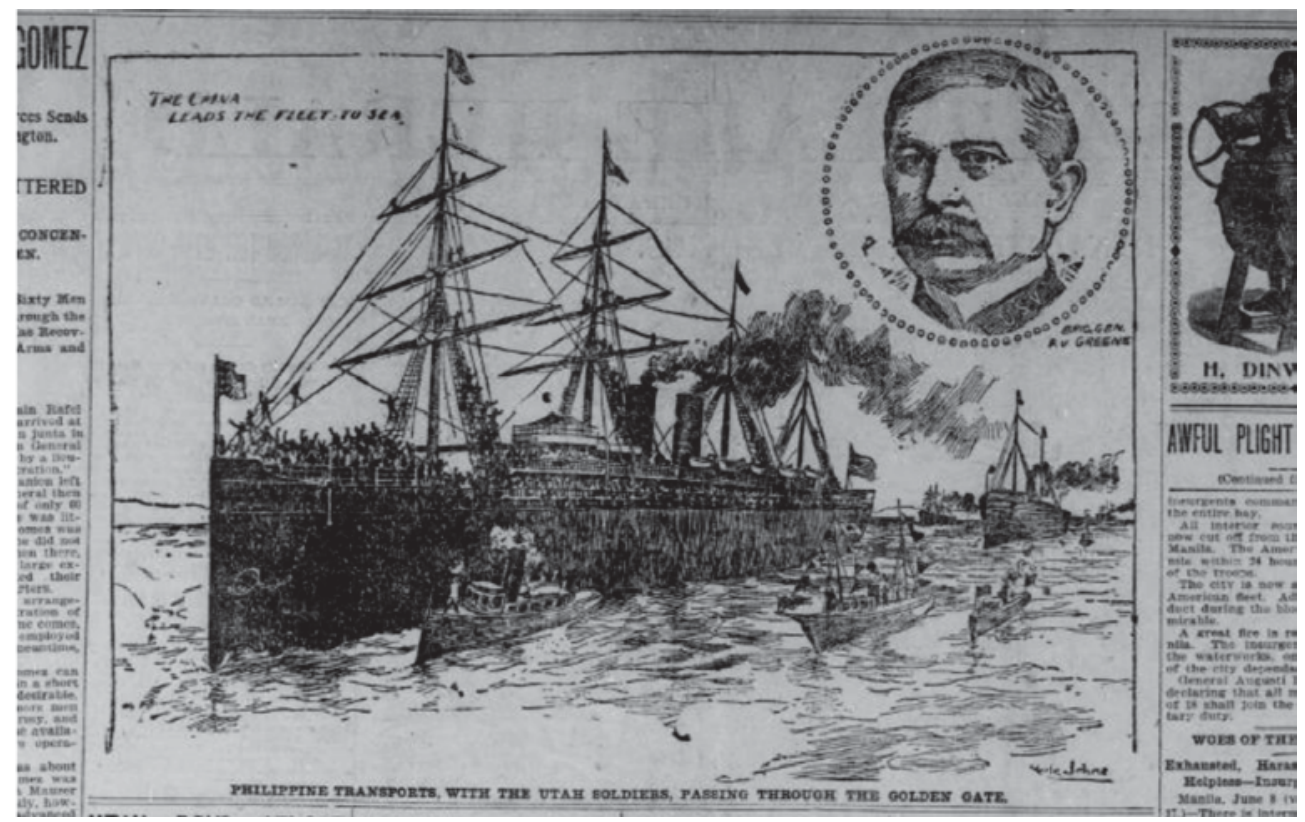

Figura 12. Convoy de vapores liderados por The China saliendo de San Francisco hacia Filipinas con las tropas de Manila. El Colón se encontraba entre ellos. Tomada de The Salt Lake Herald, junio 18 de 1898).

Un pasajero inusual en este viaje fue la perra "Utah", mascota de la brigada. Estaba acompañada por el Caporal Backman quien pasaba mucho tiempo con ella y no se cansaba de enseñar papeles que demostraban el record familiar de la perra por los últimos cincuenta años. Esta perra removía cualquier cosa portátil del barco y la traía a su habitación, depositándola para el uso de los soldados de la Sección 6. Cuando se le perdía algo a alguien solamente tenía que visitar el cuarto de Utah para encontrarlo.

Todas las mañanas se le veía a Utah haciendo sus ejercicios en cubierta y estos consistían en ser mecida alrededor de la cabeza del Corporal Beckham al 
final de un cincho largo el cual mordía con la fuerza genuina de un bulldog. Hubo muchas dificultadas en traerla a bordo y fue la única mascota que acompañó las "tropas de Manila". Se logró que navegara en el buque gracias a la amistad que uno de los soldados tenía con el capitán del barco (Ibíd).

Para finales de 1900 el Capitán McKinnon tenía ya cuatro años de comandar este buque. La carga que el Colón transportaba de San Francisco a Centroamérica era variada, aunque había mercancías que se producían exclusivamente en California y que tenían demanda en los países del Istmo. Para tener una idea de la carga promedio que era transportada de San Francisco a Centroamérica, se incluye una lista que aparece en un periódico en diciembre de 1900:

"49 cajas de manzanas, 207 paquetes de cerveza embotellada, 10 sacos de cemento, 25 rollos de cuerdas, 10 cajas de bienes enlatados, 390 latas de aceite de carbón, 94 latas de bienes deshidratados, 596 libras de fruta deshidratada, 2,415 bolsas de harina, 678 paquetes de golosinas y provisiones, 75,410 pies de madera, 11 rollos de cuero, 93 barriles de plomo blanco, 6 barriles de clavos, 71 latas de aceite, 8 latas de cebolla, 21 latas de pasta, 30 latas de pintura, 114 cajas de papas, 110 barriles de pólvora, 20 paquetes de pasas, 11 puñados (bundles) de especies, 150 latas de ¿scap?, 24 cajas de papelería, 62,977 libras de sebo, 7 cajas de aguarrás, 10 cajas de brea, 32 cajas con 3,350 galones de vino, 45 cajas de whisky, 12 cajas de molinos de viento" (TSFC, diciembre 29 de 1900).

El 24 de febrero de 1901 el Colón llegó a San Francisco con el Capitán McKinnon con sus compartimientos de carga llenos de sacos de café. Cuando estaba a unas sesenta millas mar afuera oyeron unos disparos, por lo que se dirigieron en medio de una espesa neblina y encontraron una lancha para cazar "hunting skiff" con dos individuos "medio indios" en ella. Los indios dijeron que habían perdido a su velero y le estaban haciendo señales. Se les ofreció transporte a San Francisco pero se negaron ya que dijeron que el velero para cazar focas estaba cerca y que lo encontrarían cuando se despejara la neblina (TSFC, febrero 25 de 1901).

En marzo 1 el Colón salió nuevamente hacia Panamá (Ibíd) y regresó a San Francisco el 24 de abril. Al día siguiente se anunció que este buque ya no será empleado para la ruta de Panamá, sino que de ese momento en adelante su 
misión principal será transportar inmigrantes de Los Angeles a Hawai (TSFC, abril 25 de 1901).

Desde abril de 1901 el Colón se encontraba en el Pacifico transportando mercadería e inmigrantes de Los Angeles a Hawai. La mayoría de los inmigrantes eran portorriqueños que atravesaban el Istmo y salían desde Los Angeles hacia las islas para trabajar en las plantaciones de caña y piña. El 13 de mayo llegaron 523 portorriqueños a Hawai transportados por el Colón que en esa época seguía capitaneado por McKinnon. El barco zarpó de San Francisco y llegó a Los Angeles para abordar a los inmigrantes. Después de salir de Los Angeles se dirigió a las islas llegando al muelle de cuarentena en Hawai y no se permitió a nadie bajar o subir. Tres inmigrantes murieron en el viaje. Primero los oficiales federales de cuarentena hicieron un examen y después un agente local de salud tomó la dirección de cada uno. Posteriormente fueron llevados a la estación de "Quarantine Island" (Isla Cuarentena) donde fueron fumigados y bañados en un líquido desinfectante. Sus ropas fueron pasadas por vapor. Un tripulante interesante era el Sr. Antonio Mattei Llovera quien ayudó a las fuerzas americanas en Puerto Rico durante la guerra contra España. El Sr. Llovera proporcionó información importante al General Miles para tener ventaja en un ataque a las tropas españolas. Durante el viaje hubo tres muertes y un nacimiento. "El Colón zarpará lo antes posible para traer otro cargamento de portorriqueños" (The Hawaiian Star, mayo 14 de 1901). En ese mismo periódico se menciona que esa mañana murieron en los muelles un hombre y una mujer que habían viajado en el vapor (Ibíd). Este fue el sexto viaje de inmigrantes realizado por este barco, que según este artículo tenía capacidad para transportar 800 inmigrantes (The Hawaiian Gazette, mayo 14 de 1901).

Las condiciones en el transporte de estos inmigrantes eran muy malas. En ese mismo periódico apareció un artículo titulado: "Un Lote Enfermizo y Hambriento dice Emmeluth". En esta publicación se mencionó que un congresista de Estados Unidos visitó el último grupo de inmigrantes portorriqueños que llegaron a Hawai. El congresista llegó al Colón pero los inmigrantes ya habían sido trasladados a la isla de cuarentena. El congresista se fue remando en un bote a la isla donde vio a los portorriqueños y las condiciones deplorables en que se encontraban. "Vi un niño pequeño bajo el sol hirviente evidentemente muriéndose de neumonía con sus ojos abiertos. Muy cerca estaba un hombre con demasiada fiebre para caminar y en toda la fila había personas demasiado exhaustas para caminar, débiles de enfermedad y hambre. Esas personas no 
están en condiciones para viajar (a las plantaciones)". El Congreso pasó una resolución para que los inmigrantes no fueran trasladados y se quedaran allí para investigar su condición (Ibíd). La idea de Emmeluth era que estas personas fueran alimentadas por un par de semanas y posteriormente trasladadas a las otras islas para trabajar en las plantaciones.

En mayo 29 de 1901 nuevamente apareció un artículo en el Boston Globe en el que se criticaba las condiciones en que se encontraban los inmigrantes que fueron transportados por el buque. En esta publicación se hace un llamado a la justicia y a la Corte Suprema de Estados Unidos ya que se pensaba que muchos de los inmigrantes no vivirían para trabajar en las plantaciones. "Más de la mitad de los inmigrantes portorriqueños que llegaron a Honolulu en el vapor Colón se han reportado en estado de hambruna. En cualquier caso, fue necesario retenerlos en la estación de cuarentena y proveerlos de suficiente comida para darles fuerza y que puedan llegar a los lugares que serán sus 'nuevos hogares'. Se menciona que se transportaron demasiados niños, así como hombres y mujeres que nunca estuvieron suficientemente fuertes (The Honolulu Republican, junio 26 de 1901, tomado del Boston Globe de mayo 29).

En junio 1 ochocientos portorriqueños abordaron el Colón en Los Angeles para viajar a Hawai y trabajar en las plantaciones (TSFC, junio 2 de 1901).

En julio de este mismo año se dio un caso curioso donde casi se comete un asesinato. Esto ocurrió mientras el buque se encontraba en el muelle de cuarentena en Honolulu cuando el Sr. Oppenheimer, un miembro de la tripulación del Colón fue acusado de violar a una joven inmigrante portorriqueña. El supuesto atacante pasó al juzgado, pero según el artículo donde aparece esta historia, la joven de 14 años no mantuvo un testimonio coherente y "probablemente actuó por su amor al acusado", por lo que Oppenheimer quedó libre. Sin embargo, esto no fue satisfactorio para Cruz, el hermano de la joven quien acompañado de algunos amigos se armó con un revólver y se dirigió al muelle donde se encontraba el Colón. Oppenheimer logró abordar sin que Cruz se diera cuenta, probablemente salvando su vida y manteniéndose escondido en el barco por una hora antes de zarpar. La joven trató de abordar también, pero fue detenida por un miembro de la tripulación. Finalmente, el vapor soltó los amarres y empezó a separarse del muelle. Cruz pareció haberse calmado, pero dos miembros de la tripulación le arrojaron dos botellas en la cabeza. En ese instante Cruz sacó el revólver y apuntó al buque y probablemente hubiera disparado a la gente en cubierta. En el momento que el enfurecido portorriqueño 
apuntaba al barco, Jack McVeigh le agarró el brazo hasta que Cruz guardó el arma. A todo esto la joven hermana fue una espectadora silenciosa. El Colón cruzó la península de Diamond Head perdiéndose en la distancia en su viaje hacia San Francisco (The Hawaiian Star, julio 11 de 1901).

El Colón llegó a San Francisco donde supuestamente tomaría el lugar del City of Para y así iniciar nuevamente la ruta San Francisco/Panamá. El Para tomaría la ruta de Manila. Otro buque de la PMSC sustituiría al Colón para realizar el transporte de portorriqueños. Estos cambios no se dieron ya que para agosto el Colón apareció nuevamente transportando inmigrantes puertorriqueños a Hawai. Poco tiempo después de llegar a San Francisco procedente de Hawai, el buque se encontró con una huelga generalizada por los sindicatos. Los muelles que generalmente estaban llenos de personas y mucha actividad se hallaban prácticamente paralizados, por lo que el Colón permaneció inactivo varios días (TSFC, julio 31 de 1901).

En agosto 19 de 1901 la Asociación de Agricultores de Hawai realizó una reunión donde se generaron discusiones sobre los inmigrantes que eran transportados a las islas. Es interesante notar la visión racista de la época y que al final del artículo se menciona el Colón. "Los diferentes administradores de las haciendas presentarán en detalle el status exacto de las condiciones en sus plantaciones y las diferencias claras del valor laboral de negros, portorriqueños y japoneses. Parece que se prefiere a los portorriqueños en Maui, Hawai y Kauai, mientras que se espera que las plantaciones de Maui digan que los negros son un fracaso para cortar caña.

Se espera que el vapor Colón llegue el próximo viernes de San Pedro con un gran número de reclutas portorriqueños para las plantaciones" (The Hawaian Star, agosto 19 de 1901).

A finales de ese mes (agosto 30), el Colón llegó nuevamente a Hawai capitaneado por McKinnon, con pasajeros norteamericanos y 200 trabajadores portorriqueños que serán distribuidos en las plantaciones de Oahu. Llegaron al muelle de cuarentena. "Los portorriqueños llegaron en buenas condiciones y sin duda se adaptaran a este clima". El mismo día el buque zarpó hacia puerto Los Angeles para transportar un segundo grupo de inmigrantes (The Hawaian Gazette, septiembre 3 de 1901). Entre septiembre de 1901 y marzo de 1902 el Colón es asignado para la ruta San Francisco - Panamá y el 14 de marzo de ese año el Colón es remolcado a Martínez, un lugar apartado en Panamá 
para esperar hasta que aumente el comercio con el Istmo (TSFC, marzo 15 de 1902).

El 4 de julio de 1902 se decoraron varios buques y se presentaron en la Bahía de San Francisco para celebrar la independencia de Estados Unidos. El Colón fue uno de los barcos decorados elaboradamente (TSFC, julio 5 de 1902).

El 18 de julio de 1902 salió de San Francisco con 180 toneladas de plomo dirigidas a Nueva York vía Panamá. También transportó troncos de cedro que habían estado en los muelles por algún tiempo. Estos troncos llegaron a San Francisco desde Panamá y fueron enviados allí para ser trasladados por tren a Nueva York. Esta mercancía es muy difícil de transportar por tierra, por lo que la PMSC esperó un tiempo para enviarlos nuevamente hacia Panamá y luego a Nueva York (TSFC, julio 3 de 1902).

El 1 de septiembre el Colón llegó a San Francisco con 1,210 toneladas de carga, la mitad procedente de Nueva York y un "tesoro" procedente de Mazatlán evaluado en $\$ 95,800.00$ (TSFC, septiembre 2 de 1902).

En septiembre 14 de 1902, el Colón llegó a Acapulco con varios pasajeros procedentes de San Francisco (TSFC, septiembre 28 de 1902). A su regreso desde Panamá a San Francisco el mes de octubre, el Colón pasó algún tiempo en el muelle de cuarentena y posteriormente fue estacionado en el muelle de la PMSC. En esta ocasión llevó 798 toneladas de oro y plata valorados en $\$ 60,000.00$, así como trece pasajeros.

En octubre de 1902 el Colón finalizó la colocación de la línea de telégrafo de 4,445 millas entre la Isla Vancouver y la isla Fanning en el Océano Pacífico. Posteriormente se colocó otra línea de 2100 millas conectando la isla Fanning y las islas Fiji (The Seattle Star, octubre 7 de 1902).

En noviembre, la PMSC sube los precios para viajar y transportar mercancías en el Colón (TSFC, noviembre 4 de 1902).

El 31 de diciembre de 1902 el Colón llegó a San Francisco desde Panamá con un cargamento de 1,030 toneladas que incluía 3,300 sacos de café guatemalteco. También llevó 30 toneladas de metal obtenido en las minas Rosario. Este fue el primer cargamento de este metal a San Francisco, ya que anteriormente se enviaba a Europa. En este viaje el buque no fondeó en Mazatlán ya que había 
una epidemia. Es interesante la siguiente mención: "El Colón no trae noticias nuevas sobre la situación en Guatemala. Sin embargo, el Capitán Irvine informa que en varios cientos de millas en las aguas de la costa hay gran cantidad de piedras pomas flotando" (TSFC, enero 1 de 1903). Este fenómeno natural se debió a la erupción del volcán Santa María, uno de los eventos volcánicos más grandes del siglo XX. En esta ocasión al Colón le tomó 21 días, 18 horas y 25 minutos realizar el trayecto desde Panamá y por primera vez aparece el Capitán Irvine. A su llegada los tripulantes trajeron la noticia que la revolución ha terminado y que ahora la actividad principal en Panamá es jugar ping pong (Ibíd).

El sábado 10 de enero de 1903 el Colón estaba saliendo hacia el mar por uno de los canales estrechos en Lime Point, California, cuando fue sorprendido por la marea que subía. La popa se "trasladó" demasiado cerca de las rocas y el Capitán Irvine tuvo que maniobrar el barco hasta colocarlo en la parte central del canal, salvándolo de colisionar con la orilla (TSFC, enero 12 de 1903). Durante este viaje es que llega a las costas salvadoreñas fondeando el 25 de enero en Acajutla procedente de San Francisco con el Capitán Irvine, desembarcando 670 bultos de mercadería, 8 sacos y 6 paquetes de correspondencia y varios tripulantes (Diario Oficial, 26 de enero de 1903).

El 14 de marzo de 1903, el Colón salió de San Francisco con 30 pasajeros y 2000 toneladas de carga, incluyendo 1,800 barriles de vino californiano, el cargamento más grande de este producto que había salido de aquí en varios años (TSFC, marzo 15 de 1903).

En su travesía hacia San Francisco, específicamente el 17 de abril de 1903, el Colón presenció un show impresionante consistente en inmensos chorros de agua. Los pasajeros y tripulación fueron entretenidos por varias horas por grandes chorros que salían a una distancia prudencial del buque. Tres grandes pilares líquidos sin inclinación que los hiciera acercar al barco tiraban agua hacia arriba, pero el buque pasó lo suficientemente cerca para que los viajeros tuvieran una idea de su enorme tamaño y fuerza " $\mathrm{y}$ de estar agradecidos que los elementos no escogieron el trayecto del vapor como campo de juego de estas creaciones acuáticas" (TSFC, mayo 6 de 1903). En un inicio pensé que este era un fenómeno artificial para dar la bienvenida a los vapores que llegaban a San Francisco, pero después de encontrar otro artículo en el periódico del día anterior es evidente que estos chorros de agua eran lanzados por ballenas: "El Memphis se Encuentra con unos Chorros de Agua". "El Memphis 
de la Línea Kosmos que llegó procedente de Hamburgo el día 6, experimentó chorros de agua similares por los que pasó el vapor Colón. Los grandes pilares líquidos se avistaron después de pasar por Panamá. Los oficiales del Memphis dicen que las columnas medían 30 pies desde la base y se extendían hacia el cielo hasta donde podía ver el ojo. Aparecieron a una distancia de varias millas del vapor, pero todos estaban de acuerdo que se acercaron a una distancia cómoda. Los chorros de agua vistos por el Memphis parecen haber sido particularmente divertidos. Bailaron a una velocidad furiosa y a intervalos frecuentes desaparecían en las profundidades para disparar nuevamente un poco más lejos como grandes pistones. A pesar de la distancia, se podía sentir a bordo el ruido que estos chorros hacían" (TSFC, mayo 7 de 1903). En una época en que los vapores eran las máquinas movibles más grandes del mundo, símbolo de poder industrial y avance tecnológico, es muy interesante notar como las ballenas impresionaban a los pasajeros de estos navíos.

En esta ocasión el Colón trajo noticias sobre el naufragio del Kombyses, un vapor de la Kosmos Line que encalló ocho meses antes en Cabo Blanco, Costa Rica y que fue comprado por un señor de apellido Pennel de Puntarenas por $\$ 6,000.00$. El Colón llevó a San Francisco 1400 toneladas de cargamento, incluyendo 5000 sacos de café. También llevaba trece pasajeros (TSFC, mayo 6 de 1903).

En este mismo periódico hay un espacio titulado "Los Pasajeros Bulliciosos del Colón”. Aquí se menciona que al llegar de Panamá, el Colón transportaba a 122 de los pasajeros más bulliciosos que han viajado en un buque interoceánico. Desde sus habitaciones hasta las cubiertas en todo el viaje se oía conversación en español en alto volumen mezclada con gritos y aullidos ininteligibles que variaban con llantos agudos en coro y en solos. La azafata encargada de este grupo hablantín estaba exhausta cuando llegaron a San Francisco, pero tuvo que atender al grupo hasta la mañana siguiente cuando el Tío Sam les otorgó sus documentos para entrar a la "tierra de la libertad". De estos ciento veinte pasajeros, ciento catorce eran loras, seis eran monos, uno era un oso hormiguero y el otro "un misterio de la historia natural que parece oso, escala como mono, piel de oveja, come como cerdo y tiene toda la domesticidad de un gato casero. Su forma asemeja a un perro salchicha. Pesa cerca de dos libras y duerme veintidós horas al día (probablemente un oso perezoso). Este ha sido el cargamento de pájaros y bestias más grande que se ha traído desde hace mucho tiempo" (TSFC, mayo 6 de 1903). 
El 5 de mayo, el Colón llegó nuevamente a San Francisco vía Acapulco desde Panamá. Esta travesía le toma 21 días capitaneado por el Capitán William A. Irvine trayendo noticias de Corinto, Nicaragua. Es interesante que en esta ocasión la tripulación relató sobre una batalla naval que se llevó a cabo frente a San Ubaldo y Granada en el Lago de Nicaragua, entre las tropas revolucionarias de Chamorro contra el Presidente Zelaya. Se mencionó la muerte del Capitán Augusto quien se encontraba en el barco Victoria, así como la muerte del capitán del barco El-93. "El gobierno perdió cuarenta y dos soldados y veintidós fueron heridos. Los revolucionarios pagaron su victoria con veinte muertos y ocho heridos. El 10 de marzo el General Chamorro en su lucha contra el Presidente Zelaya capturó el barco de guerra DeJulio y cuando el Colón zarpó de Corinto, Chamorro tenía el control del lago de Nicaragua (The San Francisco Call, mayo 6 de 1903).

El día 6 de mayo se descubrió escondido dentro del Colón un contrabando de opio consistente en ochenta latas valoradas en $\$ 650.00$. Esta fue la segunda vez que se involucró este buque en el contrabando de opio. Probablemente la droga fue transportada ilegalmente desde el Oriente hasta Panamá y posteriormente a California. Fue necesario desatornillar una plancha de hierro que se encontraba entre el casco y la placa interior del barco. El opio estaba enrollado herméticamente en tela para vela (canvas) y se pensaba que sería arrojado fuera de borda por la noche a otro barco que lo estuviera esperando. "Después del debido proceso por la corte de Estados Unidos, el opio será vendido en una subasta pública" (TSFC, mayo 7 de 1903).

La noche del 20 de junio de 1903, el Colón es alcanzado por un rayo frente a la costa de Costa Rica. El rayo dañó uno de los mástiles de madera que se fracturó en varios pedazos (TSFC, julio 11 de 1903). Durante este mismo viaje, el buque fondeó en San Blas, México donde abordaron el Capitán Rosengren y la tripulación del barco de vela Maggie C. Russ que naufragó en ese puerto el 11 de junio y fue se perdió totalmente. En esta ocasión el Colón solamente trajo tres pasajeros de cabina y un "tesoro" evaluado en $\$ 4,000.00$. Los tripulantes traen la noticia que la oficina de la Pacific Mail Steamship Company en Acapulco fue robada y faltaban $\$ 400.00$ "el robo es una ofensa en cualquier comunidad civilizada" decía el periódico. El asaltante golpeó al guarda y después de robar el dinero escapó. Al despertar el guarda llamó a los soldados y el asaltante fue capturado en la carretera que va hacia Ciudad de México. "El ladrón confesó el hecho y será fusilado" (Ibíd). 
El 11 de julio se anunció la salida del Colón para el día 18, zarpando desde San Francisco al mediodía por el muelle 40.

El 12 de septiembre el Colón fue dado de alta y trasladado a los muelles de la PMSC debido a que se encontraba en cuarentena y un pasajero chileno murió el día anterior. Los pasajeros y la tripulación serán detenidos por lo menos cinco días más en la isla Angel. El buque trajo 46 pasajeros, 1046 toneladas de carga y un "tesoro" evaluado en $\$ 43,485.00$ (TSFC, septiembre 12 de 1903). $\mathrm{Al}$ salir de cuarentena, el 18 del mismo mes, los oficiales del Colón y del City of Sydney informaron que Panamá está lista para su independencia de Colombia y nada puede evitar este desenlace. Los más interesados en la construcción del canal son los empresarios jóvenes que quieren separarse de Colombia (The St. Louis Republic, sept 19 y The Nebraska Advertiser, septiembre 25 de 1903). Al día siguiente (sept. 19) sale nuevamente hacia Panamá.

El 13 de noviembre de 1903 el Colón llegó a San Francisco desde Panamá después de 24 días de viaje con su Capitán Irvine. Arribó con 758 toneladas de carga y aproximadamente una docena de pasajeros que se encontraban muy impresionados ya que mientras estaban en Acapulco fueron testigos de la caída de un gran meteorito la noche del primero de ese mes. El cometa iluminó el cielo por varios minutos y fue visto también por los pasajeros de los vapores Marblehead, Concord y Wyoming que también estaban anclados en Acapulco. Durante este viaje uno de los ingenieros del barco fue picado por un escorpión, siendo el segundo ingeniero que sufrió este tipo de percance ya que lo mismo ocurrió en el viaje anterior. El doctor recomendó que se buscara en la habitación la causa de las picadas, encontrándose un nido con varios escorpiones bebés y algunos adultos. En este arribo, el Colón trajo la noticia que el barco de guerra Wyoming llegó a Acapulco con solo 12 toneladas de carbón, por lo que "la máquina de combate más moderna del Tío Sam hubiese tenido que ser remolcada por el Marblehead o el Concord" si el carbón se hubiera terminado. Cuando el Colón viajaba "hacia abajo" rumbo a Panamá, llevó treinta soldados desde Acajutla a La Unión cuyo destino era la frontera con Nicaragua en caso surgiera un conflicto entre los dos países. (TSFC, noviembre 14 de 1903). Esta vez permaneció 8 días en San Francisco y el 21 salió nuevamente hacia Panamá.

En enero 14 de 1904, apenas tres meses antes de encallar en los arrecifes de Punta Remedios, el Colón llegó a San Francisco proveniente de Panamá con las noticias de un gran desarrollo que está ocurriendo en el Istmo. Debido a 
la futura construcción del canal se estaban demoliendo casas y construyendo nuevos edificios. Los precios en los alquileres se habían cuadruplicado con prospectos de aumento a medida que progresan las negociaciones para la construcción del canal. Los tripulantes del Colón también mencionaron que un día antes de zarpar de Panamá 600 soldados colombianos estaban a un día de marcha del Darién y muchos mineros habían huido hacia Panamá porque temían un levantamiento en las minas. El Colón se encontró con el crucero New York frente a Puerto Angel el 4 de enero y al día siguiente se encontró al Bennington (vapor de guerra norteamericano que se destacaba en las costa del Pacifico centroamericano y que realizó un estudio sobre las profundidades de la bahía de Jiquilisco), al Preble y el Paul Jones. El Colón llevaba a El Salvador quince cajas de rifles Remington con bayonetas colocadas para uso gubernamental. En ese momento el Presidente era Don Pedro José Escalón y "Según los oficiales del Colón; Salvador, Guatemala, Nicaragua y Honduras se estaban preparando para una extensa y general trifulca, pero con la acción de América (Estados Unidos) en Panamá, estos países ven una advertencia de lo que puede pasar si sus peleas molestan al Tío Sam..." (TSFC, enero 15 de 1904). El Colón zarpó nuevamente hacia Panamá el 23 de enero.

La primera aparición del Colón en costas salvadoreñas durante el año 1904 fue el 8 de febrero procedente de San Francisco. Llegó a Acajutla a las 6:00 am con el Capitán Irvine, "con 75 hombres de mar", 2,090 bultos de mercaderías, 12 sacos y 3 paquetes de correspondencia y varios pasajeros (Diario Oficial, 8 de febrero de 1904). Posteriormente fondea en La Libertad el 10, con 227 bultos y sin pasajeros (Diario oficial, febrero 10 de 1904) y al día siguiente llega a La Unión con 73 tripulantes, 802 bultos de mercaderías, 4 sacos y 4 paquetes de correspondencia, así como varios pasajeros. El buque viajaba hacia el sur, por lo que es evidente que en esta ocasión el destino final era Panamá.

$\mathrm{Al}$ regreso hacia San Francisco no se tiene registro de arribos en puertos salvadoreños, pero el 17 de marzo de 1904 llegó a San Francisco después de 21 días y medio de viaje. Al acercarse, una fuerte tormenta en la costa de San Francisco hizo que el vapor esperara hasta el atardecer para ingresar al puerto. Las oficinas de cuarentena estaban cerradas por lo que tuvo que anclar frente a la isla Angel y pasó por las autoridades de migración a primera hora del día siguiente (TSFC, marzo 18 de 1904). En esta ocasión el buque trajo 1,084 toneladas de cargamento y "tesoro" extraído de las minas de México y Cen- 
troamérica evaluado en $\$ 50,513.00$. Entre sus pasajeros estaba un magnate de la madera y un cazador de cocodrilos profesional (TSFC, marzo 19 de 1904)

\section{El Colón colisiona con el City of Sydney.}

En marzo de 1904 se asignó al Colón el Oficial en Jefe Sandberz, quien antes estaba en el Siberia. Muy poco tiempo después, aproximadamente un mes antes que el Colón se perdiera totalmente en Acajtula, este buque estuvo involucrado en una colisión con el vapor City of Sydney de la PMSC, dañándose la popa del Colón, por lo que según este periódico, el Capitán Irvine fue suspendido de su puesto hasta que se concluyó una investigación sobre este percance (TSFC, marzo 22 de 1904). No he logrado establecer la fecha exacta del accidente entre los dos vapores, pero se tiene registro que el 8 de marzo el City of Sydney se encontraba en el puerto salvadoreño de La Unión dirigido por el Capitán W. H. Mclean y 70 tripulantes. En esta ocasión descargó 761 bultos de mercaderías, 29 sacos, dos paquetes de correspondencia y dos pasajeros (Diario Oficial, marzo 8 de 1904). Posteriormente zarpó de La Libertad el día 10 llevando 344 sacos de café y 3 sacos de correspondencia (Diario Oficial, 10 de marzo de 1904) y después fondeó en Acajutla. El City of Sydney zarpó esa misma noche a las 8:40 pm de Acajutla hacia San Francisco con 495 bultos, 11 sacos, siete paquetes de correspondencia y varios pasajeros (Diario oficial, marzo 12 de 1904). Su siguiente puerto de fondeo fue Puerto San José, Guatemala. Es muy probable que la colisión entre los dos buques ocurriera cuando el City of Sydney realizaba el trayecto hacia San Francisco y el Colón viajaba hacia el sur. Si el Capitán Irvine fue suspendido por este percance, tuvo que ser por muy poco tiempo ya que aproximadamente un mes después se encontraba nuevamente como capitán del Colón cuando este buque encalló en Acajutla.

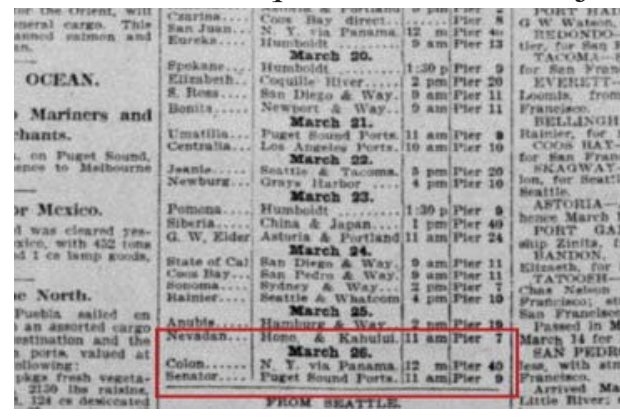

Figura 13. Anuncio de la última salida del SS Colón de San Francisco el 26 de marzo de 1904, enmarcada en el rectángulo rojo. Obtenido de TSFC, marzo 18 de 1904.
El Colón salió desde San Francisco hacia Panamá por última vez el mediodía del 26 de marzo de 1904 del muelle 40 (Figura 13). El buque nunca llegó a su destino final.

\section{Final del Colón en 1904.}

El 9 de abril de 1904 el Colón se encontraba fondeado en Puerto San José 
de Guatemala, habiendo salido de San Francisco el 26 de marzo en su ruta hacia Panamá. Esa noche se celebró a bordo el casamiento del Primer Oficial J. Wilson y en la celebración también participaron la mayoría de los oficiales y parte de la tripulación. La fiesta se llevó a cabo en la habitación del Sr. Stevens quien era bodeguero y encargado de la alacena del buque. El Primer Oficial Wilson le ordenó al Sr. Stevens abrir botellas de licor para la celebración. Al día siguiente al atardecer, el Capitán William A. Irvine, quien tenía algún tiempo de capitanear el Colón giró órdenes al Jefe de Ingenieros, M. D. Sullivan para salir a todo vapor hacia Acajutla. Dos horas después de la orden, el Colón zarpó de Puerto San José en la oscuridad de la noche hacia el puerto de Acajutla. Al acercarse a la costa, el Capitán sube al puente pero no verifica profundidades y distancia. Tampoco detiene el buque para determinar ubicación y esperar el amanecer como hubiese sido el procedimiento correcto. A las 4:56 am del 11 de abril, el Colón colisionó con las rocas del arrecife que se encuentran en Punta Remedios, Acajutla. El choque perforó el casco del barco y el agua empezó a inundar los compartimientos inferiores, por lo que el Capitán ordenó dirigirse directamente a la playa para evitar su hundimiento. El buque encalló en la playa a no más de doscientos metros al este de la bocana del río Sensunapan, entre el muelle (actualmente solo se encuentran los restos) y la desembocadura del río.

La noticia del accidente apareció en varios medios de comunicación los días siguientes al desastre, aunque la primera versión se difundió el mismo día en el Diario Oficial salvadoreño bajo "Movimiento de Buques" en Acajutla con fecha abril 11 de 1904:

“A las 6:30 am., encalló en esta rada el vapor N.A (norteamericano) 'Colón', procedente de San Francisco de 1,843 toneladas de registro, en Capitán Irwine, con 74 tripulantes. Trae para este puerto 1,413 bultos de mercaderías, 18 sacos $i^{---}$? paquetes de correspondencia y a los pasajeros Canto, L. Fajardo, A. Lindo, J. Romero, H. Pérez, B. Davidson, A. Davidson, G. Cisneros, S. González y A. Ruiz, de San José de Guatemala. - Patente limpia. El vapor está varado entre la bocana del río Grande (Sensunapan) y el muelle. Se han tomado todas las providencias del caso" (Diario Oficial, lunes 11 de abril de 1904).

Al día siguiente (abril 12) la noticia aparece en varios periódicos en Estados Unidos. En el Oakland Tribune se presenta en primera plana (Figura 12) y en 
The Times Dispatch se describe el suceso:

Otra noticia de la Associated Press: "El vapor Colón se encuentra encallado en Salvador. Por la AP." "Nueva York, abril 12. Un despacho desde Acajutla, Salvador que fue recibido en esta oficina de la Pacific Mail Steamship Comapany el día de ahora, menciona que el vapor Colón se encuentra encallado cerca de la punta. Todos los pasajeros se salvaron. La extensión de los daños al Colón no puede ser determinada hasta que se realice un examen más completo" (The Times Dispatch, abril 13 de 1904).

El periódico The San Francisco Call sin duda era la mejor fuente pública sobre acontecimientos relacionados con los buques que realizaban la ruta Panamá/San Francisco. En la edición del 13 de abril aparece la noticia de la colisión del Colón. Aquí se menciona que después de chocar con el arrecife en Punta Remedios, el buque retrocedió y el agua empezó a penetrar de una forma alarmante. "El Colón no está proveído con mamparos contra el agua." Aquí se mencionó que el vapor había salido de Acajutla, siendo este un error común en algunos periódicos de la época. No he encontrado documentos que confirmen la llegada del Colón a este puerto y si seguimos los horarios desde que zarpó de Puerto San José, todo indica que este vapor colisionó con el arrecife antes de llegar a Acajutla. Es interesante incluir aquí una cita sobre Punta Remedios: "El arrecife de Punta Remedios, donde el Colón encalló se extiende unas dieciocho millas desde la punta y es una de las peores amenazas para la navegación entre San Francisco y Panamá. Los vapores de la Pacific Mail, Nicaragua y San Blas ambos tuvieron dificultades en este arrecife que también escupió al buque Kambyses de la Línea Kosmos." (TSFC, abril 13 de 1904). Ahora sabemos que el SS San Blas encalló en la Punta Comasagua en el departamento de La Libertad, a unos 50 kilómetros hacia el este de Punta Remedios, en la playa que actualmente lleva el nombre del vapor ${ }^{12}$.

Los pasajeros a bordo en primera clase en el Colón eran: Srta. C. N. Powell, Srta. H. Olafson, O. A. Rowan, W. S. Vincent, Srta. F. Schmid, Teniente E. W. Wood, M. T. C de Chasse, Reverendo y Sra. H. Painter, Reverendo y Sra. S. V. Dille. Aparte de estos pasajeros había veintisiete en tercera clase y un número de Chinos que viajaban hacia Nueva York. Aquí se menciona que el Capitán Irvine había trabajado en la PMSC por 25 años (TSFC, abril 13 de 1904). Sin duda, la información que más llama la atención en este artículo es una fotografía del Colón (Figura 13).

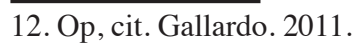




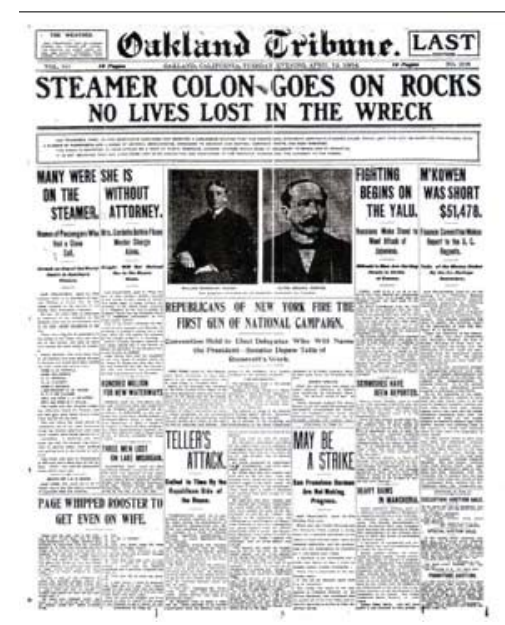

Figura 12. Portada del Oakland Tribune, abril 12 de 1904.

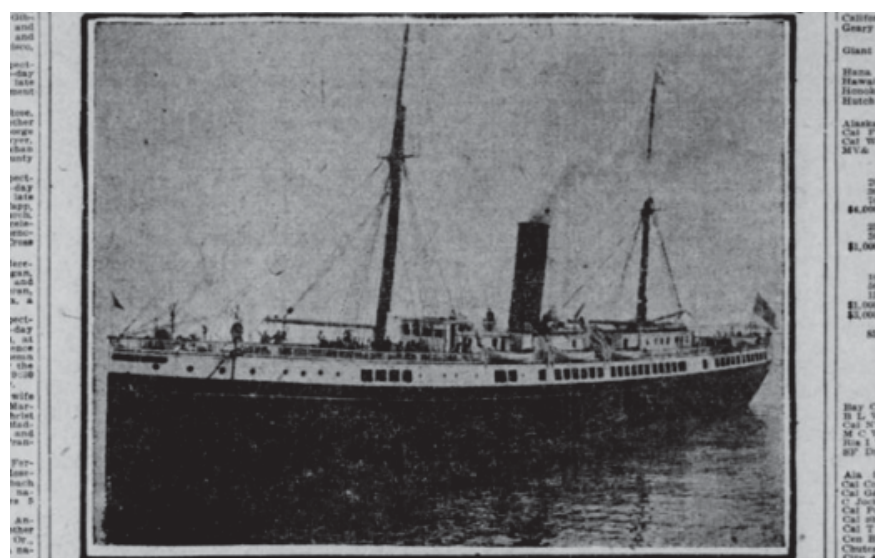

Figura 13. Noticia sobre el naufragio del Colón con una fotografía del vapor. Tomada de The San Francisco Call, abril 13 de 1904.

Otra noticia posterior: "El vapor Colón que se dirigía a Panamá con pasajeros y carga chocó contra una roca en Punta Remedios temprano esta mañana. El vapor quedó encallado en la playa de Acajutla. No se perdieron vidas aunque los pasajeros se encontraban en un estado muy alterado cuando el vapor chocó. El cargamento se está extrayendo y la mayoría será salvado" (Hilo Tribune, abril 22 de 1904).

El 14 de abril de 1904 salió de Panamá el vapor Aztec de la PMSC para auxiliar al Colón que se encontraba varado en la playa. El buque se encontraba 
atascado en la arena con un agujero en el casco, por lo que fue una pérdida total y la ayuda debió ser muy limitada (TSFC, abril 15 de 1904).

Al día siguiente (15 de abril) aparece un artículo titulado: "Un Navío Encallado", "El vapor Colón encalló en el arrecife de Punta Remedios". Es interesante notar que en esta noticia se mencionan los naufragios Nicaragua y Cheribon (Cherboon) que fueron perdidos en el arrecife de Los Cobanos años antes. A continuación se presenta la traducción: "Panamá, abril 15 - El vapor Colón de la Pacific Mail Steamship Company encalló en Punta Remedios, en el mismo lugar donde el vapor americano Nicaragua y el navío inglés Cherboon (Cheribon) fueron perdidos. El Capitán Irvine logró escapar de Punta Remedios, el Colón se encuentra actualmente en la playa cerca del muelle de Acajutla, a tres millas de Punta Remedios. No se conocen otros detalles sobre el suceso" (The Bourbon News, abril 15 de 1904).

En esta época los vapores eran máquinas impresionantes de alta tecnología y representaban el progreso industrial y económico de las grandes naciones. Los capitanes de estos buques de gran tamaño generalmente eran personas vistas por la sociedad como honorables, confiables y con experiencia, especialmente aquellos que trabajaban para las grandes empresas como la PMSC. Muchos de ellos tenían amigos influyentes en puestos políticos importantes. Cuando estos navíos sufrían accidentes, los medios de comunicación eran muy precavidos y muchas veces generosos con los capitanes, inclusive cuando sus errores habían ocasionado el accidente. Este fue el caso del SS San Blas que encalló en la costa de La Libertad debido a una equivocación del capitán. Sin embargo, en un inicio los medios de comunicación de la época expresan buenos comentarios y admiración al Capitán Joseph Cattarinich del San Blas, que según la información en los documentos se equivocó al ver luces en la playa y creyó que había llegado al puerto de La Libertad. Debido a esta confusión, el buque se acercó demasiado a la playa y encalló en las piedras de la península de Comasagua, lugar que actualmente se conoce como la playa San Blas en La Libertad ${ }^{13}$.

El mismo fenómeno ocurrió con los medios en el caso del Colón. Aunque sin duda el Capitán Irvine tenía mucha experiencia y había salvado su embarcación más de una vez, como fue el caso del sábado 10 de enero de 1903 cuando el buque estuvo a punto de encallar en Lime Point, California. En esta ocasión el buque pasaba por un estrecho canal para salir al mar, pero la 13. Ibíd. 
marea estaba subiendo y la popa se acercó demasiado a las rocas, por lo que el capitán maniobró y colocó el vapor en el centro del canal (TSFC, enero 12 de 1903).

En el periódico The Bourbon News aparece la siguiente historia: "San Francisco, abril 13 - El vapor Colón está bajo el mando de William A. Irvine, uno de los maestros más antiguos en el servicio de la Pacific Mail Steamship Company. El ha estado en comando por años en vapores de la ruta de Panamá y es considerado uno de los navegantes más cuidadosos de la Línea. Había una extensa lista de pasajeros en la cabina del buque cuando salió de su puerto, pero la mayoría se dirigían a puertos al norte de Acajutla. Sin embargo, aquellos que salieron de aquí en el buque iban hacia Panamá y debieron estar a bordo del vapor cuando encalló. Ellos eran: Srita. C. N. Powell, Srita. H. Olofson, O. A. Rouran, W. S. Vincent, Miss F. Schmid, Liet E. W. Wood, M. T. C. De Chasse, Rev. y Sra. J. H. Printer y Rev. y Sra. S. U. Dille.

El buque había salido de Acajutla (aquí aparece un error ya que en realidad el buque salió de Puerto San José en Guatemala y nunca fondeó en Acajtula) el lunes en la tarde dirigiéndose a Panamá y solamente había recorrido unas 15 millas cuando golpeó una piedra. El arrecife donde golpeó el buque es considerado uno de los más peligrosos en la costa centroamericana y muchos barcos han encontrado sus tumbas allí. Según hombres de mar que conocen el arrecife, el vapor fue desafortunado después de chocar contra el arrecife y llevarlo posteriormente al puerto de Acajutla.

El Colón fue construido en Fildadelfia en 1873 y era un barco 'hermano' del Colima, que se perdió frente a Manzanillo hace unos siete años. El Colon fue uno de los primeros vapores de la Pacific Mail usado como transporte cuando los Estados Unidos necesitaban barcos para transportar soldados hacia las Filipinas. Ella realizó muchos viajes en el servicio de transporte. Una gran cantidad de navíos han chocado en el Arrecife Remedios donde el Colón encalló" (Ibíd). La suerte de Irvine parecía estar echada desde el choque con el City of Sydney casi un mes antes.

A diferencia de la pérdida del vapor San Blas casi tres años antes, el accidente del Colón fue causa de indagación y juicios para encontrar culpables. Fue necesario hacer una serie de sesiones con testigos y efectuar una investigación formal para determinar las circunstancias y culpabilidad en el desastre. 
A principios de junio se anunció que la primera sesión fue suspendida hasta el 6 de ese mes en la mañana ya que el Ingeniero en Jefe M. P. Sullivan no se encontraba y los ingenieros exigían su presencia. A Sullivan se le acusaba de intoxicación y negligencia en su trabajo y el Primer Oficial Wilson se le acusaba de haber pagado al bodeguero $\$ 100.00$ para entregar licor a los presentes. "La investigación promete ser de gran interés" (TSFC, junio 7 de 1904).

El 28 de julio de 1904 se efectuó una sesión en la que participaron inspectores de Estados Unidos. En esta reunión se presentó un nuevo testigo: J. M. Campbell, Segundo Asistente del Ingeniero. Según su testimonio, el capitán del Colón, los tres ingenieros, el primero, segundo y tercer oficial, así como el resto de los tripulantes que navegaban el barco estaban sobrios, mientras el whisky y champán consumido para celebrar el casamiento del Primer Oficial Wilson fue proporcionado por H. G. Stevens, el bodeguero y algunos otros que estaban borrachos. Después de esta sesión inicial, los inspectores decidieron no dar un veredicto y se comprometieron en proporcionar una solución en un futuro cercano.

En este juicio, el Capitán William A. Irvine dijo que el Ingeniero, W. D. Sullivan debió haber equivocado sus órdenes para acelerar el vapor a cuarenta revoluciones por minuto y lo llevó a cincuenta, por lo que el Ingeniero tuvo la culpa de la pérdida del barco (TSFC, julio 29 de 1904). En forma resumida, en esa primera sesión la culpa del desastre cayó en el bodeguero por haber proporcionado el licor y en el Ingeniero Sullivan por haber equivocado la orden sobre la velocidad.

El 12 de agosto los inspectores locales Bolles y Bulger llegaron a una conclusión sobre los acontecimientos que causaron la pérdida del buque en base al testimonio del Sr. Stevens, el bodeguero. Este veredicto apareció en un artículo titulado "Ebriedad a Bordo" en TSFC, agosto 13, 1904. En esta sesión el Sr Stevens atestiguó que el Primer Oficial Mr. Wilson le ordenó abrir botellas de vino para los presentes. También testificó que se abrieron treinta y tres botellas de champán, cinco botellas de whisky y algunas botellas de ginger ale, todas consumidas en su habitación entre las 9:30 pm del 9 de abril y las 2:00 am del día siguiente. El Sr. Stevens también aseguró que el primero, segundo y tercer asistente estaban bajo la influencia del licor. "Estamos inclinados a dar crédito a la evidencia presentada por el Sr. Stevens aunque no está corroborada por otro testigo ya que cuando se les daba la oportunidad a los 
demás involucrados de estar presentes en la audiencia final para interrogarlo sobre su testimonio, ellos declinaban esta oportunidad" (Ibíd).

Se llegó al dictamen que el Capitán Irvine fue culpable de negligencia y falta de destreza por lo que su licencia de piloto fue suspendida por 12 meses. La licencia del Primer Oficial J. Wilson fue suspendida por cuatro meses, el Tercer Oficial J. W. Taylor fue exonerado de culpa. La licencia del Ingeniero en Jefe, D. E. Sullivan fue suspendida por cuatro meses y las licencias de los ingenieros asistentes M. D. Sullivan, J. M. Campbell y Daniel Farley fueron suspendidas por noventa días. El valor del buque fue estimado en $\$ 150,000.00$ y la carga en $\$ 60,000.00$, parte de la cual fue recuperada. A continuación se presenta una traducción de la resolución:

"Si el Capitán Irvine hubiera tomado una decisión cuando subió al puente a las 4:52 am, o hubiera detenido el barco y esperar hasta el amanecer como lo hubiese hecho un capitán más cuidadoso, hubiera determinado la posición del buque. El Capitán Irvine había dicho que su conocimiento sobre la ubicación del barco se basaba totalmente en la orden que había dado al Ingeniero en Jefe de acelerar a 47 revoluciones por minuto. Esta orden fue girada mientras se encontraban en Puerto San José de Guatemala. Irvine testificó que nunca verificó si la orden fue ejecutada en cuanto a las revoluciones; que no tomó ninguna consideración en cuanto a la distancia que se había recorrido desde San José en base a la bitácora y que no le dio importancia al informe proporcionado por el Tercer Oficial, el Sr. Taylor sobre la distancia entre el vapor y 'la luz' (costa) a las 4:52 am ya que no tenía confianza en la habilidad del Sr. Taylor. Según el Capitán, el Colon se encontraba entre 71/2 y 73/4 millas de la costa.

Después de un escrutinio detallado del testimonio tomado en este caso, encontramos que el Capitán William A. Irvine fue negligente y falto de destreza en navegar el vapor Colon el 11 de abril de 1904 y por haber depositado su confianza absoluta en una orden verbal dada al Ingeniero en Jefe William D. E. Sullivan dos horas y media antes de zarpar de Puerto San José en Guatemala; al no tomar medidas para determinar si estas órdenes se estaban cumpliendo una vez el barco estaba en marcha, especialmente cuando él atestiguó que el Sr. Sullivan estaba bajo la influencia de licor al momento que se le dio la orden para zarpar a cuarenta y siete revoluciones. También al no considerar la distancia del buque cuando subió al puente a las 4:52 am tomando como referencia la bitácora que demostraba la salida de San José y al desestimar 
el informe del Tercer Oficial, el Sr. Taylor, sobre la ubicación del buque sin tomar profundidades o detener el barco hasta el amanecer como debió hacer en estas circunstancias." (TSFC, agosto 13 de 1904).

El Primer Oficial J. W. Wilson también fue declarado culpable por mal comportamiento la noche del 9 de abril al dar instrucciones al bodeguero, H. G. Stevens en proporcionar licores y cerveza a los oficiales y tripulación; por no detener al bodeguero al repartir más licor cuando los presentes ya estaban ebrios; por beber con oficiales y por no informar al capitán del barco sobre la situación que existía a bordo. La fiesta terminó en desastre.

El 9 de julio de 1904, el vapor de la PMSC Barracouta arriba a San Francisco con el Dr. Estes quien viajaba en el Colón cuando encalló en Acajutla (TSFC, julio 10 de 1904).

\section{Otros barcos con el mismo nombre.}

Era común que después de perder un barco se asignaba el mismo nombre para otro buque. Dos años después del naufragio del Colón que pertenecía a la PMSC aparece otro vapor con el mismo nombre. El México era un vapor que pertenecía a la New York and Cuba Mail Steamship Company y que posteriormente fue asignado con el nombre "Colón". A diferencia del "primer" Colón, este tenía dos chimeneas y era de mayor tonelaje (Figura 13).

Durante la guerra de 1898 , la fuerza naval española contaba con un navío de guerra llamado Cristóbal Colón que fue contemporáneo con el Colón al que se refiere este informe. Este vapor era comúnmente llamado simplemente "Colon" en los medios de comunicación. Después del atentado que hundió el buque de guerra Maine

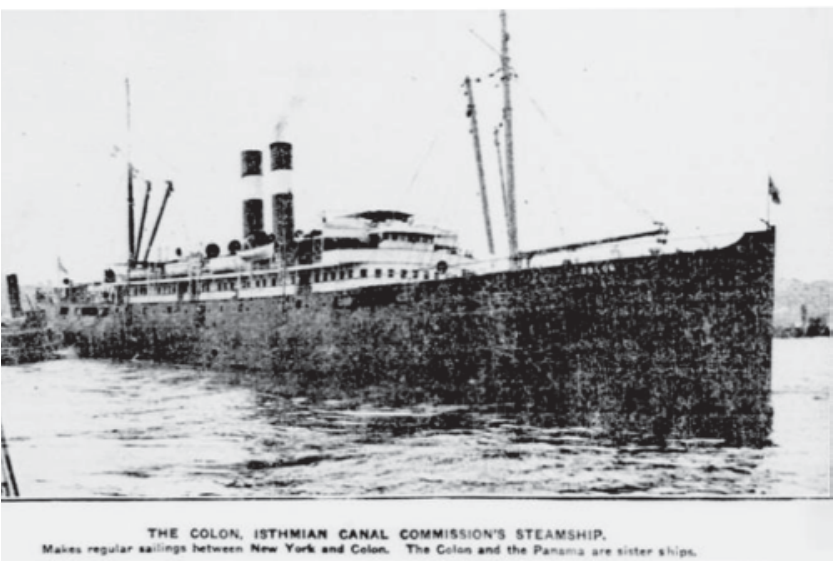

Figura 13. Fotografía del México, posteriormente nombrado Colón (New York Tribune, septiembre 29 de 1907). en la Bahía de la Habana, 
algunos medios de comunicación mencionaron que el Cristóbal Colon estuvo involucrado en este acontecimiento (The Times, marzo 4 de 1898) ya que la versión estipulaba que el buzo responsable de colocar la carga explosiva en el Maine fue abastecido por los españoles en el Cristóbal Colón y después se arrojó al mar a colocar el explosivo.

La existencia de estos dos vapores, uno de ellos contemporáneo con el Colón al cual pertenecen los restos que se encuentran en Acajutla, puede generar confusión en la investigación histórica de estos buques.

\section{Historia ficticia pero amena sobre el Colón.}

El domingo 20 de agosto de 1893 aparece una historia en la que el vapor Colón es uno de los personajes principales. El autor del artículo firmó solamente como "Claude" y este documento es incluido en este informe ya que nos proporciona datos interesantes de la vida a bordo y algunas circunstancias que los viajeros tenían que afrontar en estos viajes. El relato toma lugar abordo del Colón cuando viajaba entre Aspinwall y Nueva York. A continuación la historia tal como apareció en The Morning Call:

\section{"El Cardán Quebrado. \\ Una Historia de Mar"}

“Cupidos cafés pequeños ¿no tía?’ Una frase con una risa alegre enmarcó la oración con música y las palabras y tonos alegres fueron la primera indicación que habían otros pasajeros en la inmediata vecindad al joven hombre que estaba sentado bajo el sotavento de una lancha salvavidas en la cubierta del vapor Colón de la Pacific Mail Steamship Company. El miró inmediatamente a su habano. No, el humo no traicionará su presencia ya que el leve viento lo llevaba hacia la proa y lejos de las dos personas que habían llevado sillas para colocarlas bajo la sombra protectora de otra lancha salvavidas, cuyo casco mantenía afuera los rayos quemantes del sol.

En esta época el Colón realizaba viajes entre Nueva York y esa ciudad conocida por todos los americanos como Aspinwall, aunque el nombre haya sido cambiado para satisfacer algunas fantasías inglesas. En este momento el Colón estaba amarrado en el muelle recibiendo las últimas toneladas de cargamento - una gran cantidad de bananas verdes. El tren de Panamá recién había llegado y los pasajeros que habían tomado la ruta marítima desde San Francisco ya 
estaban subiendo a bordo. Las dos mujeres cuya conversación había interrumpido los pensamientos del hombre del habano fueron las primeras en llegar y ya se estaban poniendo cómodas. Raymond Curtis había estado a bordo dos días. El había llegado de Callao, donde realizó un viaje de negocios y el vapor Islay de la Pacific Steam Navigation Company había arribado hace cuatro días en el lado Pacífico del Istmo. Dos días en Panamá habían sido suficientes y otros dos días en Aspinwall parecían peor. El calor era demasiado intenso hasta para esta región. El Istmo nunca se cocina por los rayos del sol. Primero deja caer por media hora una lluvia caliente, lo que hace pensar a uno que la naturaleza abrió el chorro de agua caliente por equivocación; después sale el sol y eleva la humedad hasta que ha salido suficiente para generar otro aguacero. Por lo que parece que llueve todo el tiempo, primero de abajo y después de arriba, un baño de vapor continuo. Al momento que se hizo la afirmación anterior el sol se estaba metiendo y haciendo buen uso de su tiempo. Un grupo de trabajadores sudados estaba corriendo en el muelle, meciéndose en los puñados de bananas. Ellos estaban desnudos desde la cintura hasta la bandana que usaban en la frente, parecían estar hechos de caoba pulida. Jugando en unas pacas que se encontraban a una distancia atrás había media docena de niños. Siguiendo la costumbre de la adolescencia en Aspinwall estaban vestidos como llegaron a este mundo, solo en sus pieles apretadas color café. Estos eran los 'pequeños cupidos café' referidos por cierta persona y el Sr. Curtis escuchaba para una futura conversación. Pero en este momento lo que ocurre en los vapores oceánicos es que aparece el marinero de cubierta y con un 'disculpe señor; por favor mueva su silla', empezó a barrer la cubierta que ya estaba limpia cerca del lugar donde se encontraba el joven hombre. El sonido hecho por el movimiento trajo la atención de la más joven de las mujeres. Su bonita cara se sonrojó mientras recordaba la frase hecha por su acompañante: 'Vamos tía, el sol está muy caliente; entremos al salón social.'

Las dos desaparecieron y Raymond Curtis se dirigió a buscar al capitán con quien había entablado una amistad rápidamente. Mientras pasaba por el lugar donde las dos habían estado sentadas, notó algo resplandeciente en la cubierta. Se agachó y recogió un objeto elástico que estaba agarrado a una hebilla plateada. No, nadie estaba viendo así que la metió en su bolsa y continuó su paseo en la cubierta.

En la cabina del piloto, llena con cartas náuticas estaba el Capitán Griffin. 'Estaremos afuera de este agujero en una hora o dos Sr. Curtis.' dijo él, 'y después la fresca brisa marina.' 
Hablaron algunos momentos de cosas sin importancia y Curtis interrumpió la plática para contar como el Colón había sido interrumpido en su viaje al mar debido a un 'norteño,' al exclamar: ¿Quién es esa joven bonita que viene de un buque de Frisco (San Francisco) y viaja con una mujer más adulta?'

¡Ajá! ¿Con que así es la forma que el viento sopla? ¿No es así? Pensé que usted no se veía tan aburrido. ¿Y usted realmente cree que tendrá algún interés en el viaje después de todo? Ellas son tía y sobrina. Han estado en una visita de tres meses en la costa del Pacifico, donde vive el padre de la joven. Ellas vinieron conmigo hace cuatro viajes y los fuertes estudios en un seminario han afectado su salud, pero creo que ha mejorado, ¿No cree usted?'

'Capitán, ¿Puede arreglar las sillas en la mesa para yo poder estar cerca de ella?'

'Déjeme ver, yo había pensado colocar a la Srta. Thorndyke a mi derecha, después la Srta. Campbell y después usted.'

¿¿Pero, cómo podré estar cerca de la Srta. Thorndyke de esa forma?'

¿iCerca de la Srta. Thorndyke!? Pero, que Dios lo bendiga, la Srta. Thorndyke es la tía, la hermana de la madre de la Srta. Campbell, una criatura feliz y gorda que pasa mareada todo el tiempo. La Srta. Campbell, - Minnie Fay Campbell - es la bonita. Nominalmente la Srta. Thorndyke estará a mi derecha, pero esta tarde antes de la cena, estará guardada en su habitación, y excepto en días extremadamente calmados, solo la azafata la ve de vez en cuando. Así que yo tendré una buena vista de la joven dama y usted también.'

'Gracias' dijo Curtis. ‘¿Desea un habano?'

'Esto es un descarado chantaje, pero esos puros suyos son tan buenos que lo voy aceptar.'

'Minnie Fay Campbell,' decía Curtis a sí mismo media hora después.

Ese gong infernal que siempre advierte a las personas que no van a viajar que se bajen del buque, siendo también muy a menudo la señal para que caigan lágrimas, interrumpió sus pensamientos y subió al puente, donde el Capitán Griffin le otorgó el privilegio de pararse. Pero nadie lloró al salir de Aspinwall y todo el mundo se sintió mejor cuando el vapor apuntó hacia una brisa del noroeste y aumentó su velocidad justo lo suficiente para que el espray de agua cayera sobre la popa. Eso sí, siempre hay personas que pasan miserables cuando viajan en barco. La Srta. Thorndyke era de este tipo. A ella le agradaba relatar las muchas veces que había atravesado el Atlántico, pero cada histo- 
ria podía ser condensada a hora tras hora acostada en el camarote de abajo chupando pedazos de hielo, tomando una gota de jugo de limón y de vez en cuando una galleta y consomé. De vez en cuando viendo por la pequeña escotilla, primero al mar verde y después al cielo azul o nublado mientras el barco se movía de lado a lado. Se había convertido en costumbre tirarse sobre el camarote antes que la tierra se perdiera de vista y por lo tanto ella no pudo llegar a la cena esa noche.

'Pobre tía' decía la Srta. Campbell, 'me temo que pasarán varios días antes que ella esté en una mesa.'

El Capitán Griffin expresó algunas palabras de simpatía aunque no parecía muy preocupado y después la presentó al Sr. Curtis. Por educación, ella no demostró que había reconocido al hombre al que había interrumpido en la cubierta y los tres empezaron una amena conversación. Al cuarto día en el mar ocurrió uno de esos cambios drásticos. El viento murió y el mar se convirtió en un vidrio; era como navegar en un lago. El calor aumentó por lo que el toldo se colocó en la cubierta superior y las sillas fueron colocadas en orden. Parecía como que más pasajeros habían subido al barco durante la noche, se veían tantas caras nuevas. Raymond Curtis y la Srta. Campbell se divertían viendo y hablando de las personas que Neptuno había sacado de las cabinas de abajo. En la mesa de almorzar todas las sillas estaban ocupadas, hasta la Srta. Thorndyke que recibió ayuda de la azafata para colocarse en la mesa. Había muchas risas y mucho optimismo que todo el viaje sería muy tranquilo y solamente el ritmo de la hélice mientras cortaba el agua acompañaba la plática.

'Srta. Thorndyke, pruebe algo del curry,' dijo el capitán. El pasó el plato y lo estaba colocando a la par de la Srta. cuando lo dejó caer en la mesa y saltó sobre sus pies. Al instante todas las caras se pusieron pálidas, ya que parecía que un poder infernal pegaba golpes constantes al casco de la nave, mientras la masa de hierro temblaba bajo el ataque. Este ruido horrible parecía continuar indefiniblemente, pero en realidad había terminado antes que el capitán y el ingeniero habían llegado a la cubierta. Ambos habían empezado al mismo momento. Luego hubo silencio, más callado y temeroso que los golpes ya que hasta el sonido seguro y constante de la hélice no se escuchaba. Las mujeres y niños lloraban y los hombres se veían solemnes. Los oficiales que se habían quedado en el salón hicieron lo posible para calmar a la gente. 'Solamente un ligero accidente en la maquinaria,' Dijeron ellos. 'Estaremos bien en pocas horas.' 
Instintivamente la Srta. Curtis se había arrimado a su compañero durante esos momentos de angustia y nadie se había dado cuenta sino hasta después, que había colocado su brazo alrededor de ella.

'Vamos Raymond, ayúdeme con la tía,' dijo un momento después. Debido a tres días y tres noches de mareos, la Srta. Thorndyke se había desmayado en su silla, pero igual pasó con otras mujeres y las más fuertes trataban de ayudarles. Después de diez minutos apareció el capitán: 'El cardán se ha quebrado,' dijo, 'pero no hay peligro ya que no hay daño al casco. La quebradura es en el collar donde no podemos alcanzarla y la única solución es proseguir con velas. Tenemos suficientes provisiones y debemos hacer lo mejor de la situación y rezar por buen clima.'

Algunos hombres estaban molestos por el percance. Las horas de algunos de ellos eran preciosas y unos días más en el mar significaba pérdidas. Una pequeña mujer al final de la mesa lloraba incesantemente. Su esposo estaría en el muelle el día que el Colón debía arribar. ¡En qué agonía estaría! Pero antes del anochecer todos parecían contentos y estaban preparados para hacer lo mejor de la situación. Curtis estaba muy contento por el atraso, aunque mantenía los pensamientos para sí mismo. En un momento de terror ella lo había llamado 'Raymond.' Y él - bueno, ahora pensaba que podía convencerla de usar ese nombre para siempre. 'Capitán,' dijo él una hora después del accidente, ¿¿No es extraño que el cardán se quebrara durante un clima tan tranquilo?' 'Si, no es común, pero supongo que se dañó un poco durante la tormenta en el último viaje y la rajadura se fue agrandándose desde entonces. Fue afortunado que ocurrió durante buen tiempo y no durante una tormenta.' ¿Qué tan rápido podemos viajar con velas?' 'Oh, tal vez cuatro o cinco nudos. Usted entenderá que en estos tiempos de vapor no llevamos mucha vela (canvas). Actualmente, apenas avanzamos lo suficiente. Pero si los vientos promedios se mantienen, podríamos llegar a Navesink y obtener un remolcador. Son tan pocos los vapores que recorren esta ruta que probablemente no vamos a ver alguno, excepto algunos veleros. Todo lo que necesitamos es buen tiempo. No habrá peligro a menos que una tormenta llegue y entonces usted sabe lo que pasará si nos llevan las corrientes marinas.' Curtis asintió, pero él estaba pensando en Minnie que por un momento salió y recibió los rayos de sol.' 'Una escena bonita,' dijo el capitán. 'Tan bonita como uno lo deseara.' 
La joven llegó nuevamente y dijo: 'Capitán, usted y el Sr. Curtis vengan a jugar al herrón. Deben hacer algo para interesar a los pasajeros.' Aceptaron ambos riendo y un anochecer alegre fue el desenlace de una tarde de terror. Por cinco días la fortuna parece haber estado con el Colón. El viento procedía del sureste y con un poco de vela hacía unas cien millas por día. El domingo en la mañana el viento estaba muy fuerte y el Colón viajaba rápidamente. Todas las velas trabajaban bien y el capitán les aseguró a todos que este viento favorecía al buque. A las diez en punto la bandera de Estados Unidos se tendió en un escritorio en el salón de cenas y una gran biblia se abrió. Un sacerdote episcopal empezó sus servicios. Las bellas palabras fueron repetidas y luego lo divino llegó cuando se dijo la frase solemne: 'para aquellos en el mar.' Justo cuando empezaba, Curtis se dio cuenta que un oficial habló con el Capitán Griffin. El joven, que estaba sentado cerca también se levantó y salió. 'El Primer Oficial lo necesita en el puente señor,' dijo el marinero. El comandante se apresuró y después fue a su habitación donde Curtis lo siguió.

'Tal como lo había temido, allí viene. El vidrio (mar calmado) está desapareciendo rápidamente. Lo tomaremos pronto. Quiero que usted baje y después de los servicios diga a la gente que no tiene que alarmarse si oyen voces en cubierta, ya que tenemos que arreglar las velas.'

Curtis hizo lo que le dijeron y en diez minutos regresó. La Srta. Campbell, con un impermeable subió al puente con él.

'Capitán,' dijo ella, 'vamos a tener una tormenta y quiero estar aquí arriba. Como ve, no tengo ni un poco de miedo. No me pondré en su camino y no quiero estar dentro de un cuarto.'

El capitán exclamó, 'pero su tía...' 'Oh, la tía está en un estupor, apenas sabe lo que está pasando.'

'Bueno, se puede quedar. Curtis, cuídela.' Después: 'Alrededor con esas yardas; metan las planchas de estribor; rápido hombres.'

Estas palabras fueron lanzadas, puesto que el viento del sur repentinamente cesó. Las velas estaban moviéndose de un lado a otro y al noroeste un banco de nubes se estaba moviendo hacia ellos muy rápido. 
No, no eran nubes, era agua - agua que era lanzada hacia la parte superior de las olas por el fuerte viento.

¡¡Suelten todo!' gritó el capitán. Para este momento la tripulación de veinte hombres había sido reforzada por oficiales, bomberos, ingenieros y algunos pasajeros. Curtis dejó el puente y ayudó. Cuando Curtis subía nuevamente al puente, una ola de espray pasó sobre el vapor. Agarró a la pequeña mujer que parecía torcerse con la furia del viento, ayudándole a resistir la fuerza. Sobre estribor avanzaba el Colón y el agua llegaba a niveles altos en la cubierta cuando caían las olas. El mástil principal se doblaba como un asta de bandera; luego hubo una descarga como la de un cañón y el buque se movió hacia la derecha un poco. La vela fue arrancada del mástil.

'Mejor baje, este no es lugar para usted dijo Curtis mientras ayudaba a la dama a bajar. Ambos estaban empapados, pues el aire estaba lleno de agua salada y la cubierta estaba llena de espuma. Para mientras, los marineros afianzaban las velas y el Colón logró un avance constante.

En el salón había un silencio de muerte y uno que otro lloriqueo. Los pasajeros estaban conglomerados esperando. No hay nada más temeroso que esta inactividad, esta espera durante una tormenta en el mar. Toda la tarde aumentó la tormenta y el vapor empezó a moverse repentinamente con el movimiento del mar. Las olas entraban por la cubierta y el agua bajaba por las aperturas a los pasillos. Como a las cinco, el Capitán Griffin bajó para tomar una taza de café y susurró a Curtis: 'estaremos bien si las velas soportan.'

La Srta. Campbell se dio cuenta de esto y cuando el capitán se había retirado le preguntó a Curtis qué había dicho. Curtis le contó. Esta joven que apenas salía de su adolescencia estaba demostrando gran valentía. ‘ YY si las velas se rompen? Oh, yo sé, he oído hablar sobre las corrientes del mar.'

Pero ella no parecía temerosa, y con la asistencia de Curtis le daban ánimos al resto de los pasajeros, riéndose cuando las azafatas pasaban alguna comida dificultosamente ya que era imposible arreglar las mesas. La primera parte de la noche era como el día. El viento pasaba violentamente por los mástiles y el aullido se mezclaba con el rugido de la madera y las caídas de agua, interrumpido por un fuerte golpe de una ola que chocaba contra el vapor, lo que prácticamente paraba el buque por un instante. Uno a uno los pasajeros caían en sueño, algunos en el piso y otros sobre los sofás. Algunos conglomerados 
en las esquinas. A la media noche había otro informe. Curtis sabía lo que significaba y al mirar a su acompañante dedujo que ella también. Nadie puso atención a esto debido al constante ruido. 'Vamos a la parte superior de las escaleras' dijo Curtis.

Ella lo acompañó. Un techo cubría el pasillo de las escaleras. Era fuerte y bien protegido. Por las ventanas al frente podían ver el mar con sus fuertes olas blancas. La luna apareció entre las nubes y descubrió la verdad: la vela principal no estaba. Algunos hombres con el agua hasta las rodillas lograron llegar al mástil principal. El Capitán Griffin en el puente con el audífono en mano daba órdenes a los hombres, pero sus gritos no podían oírse. Mientras el Colón se inclinaba, en un momento estaba abajo y en otro sobre ellos. Parecía un espectro bajo la luna.

'Están tratando de colocar la vela' dijo Curtis.

De forma cuidadosa y despacio se desenrolló la tela de la vela y se hinchó como un globo. Las cuerdas fueron estiradas y fijadas. La proa del Colón estaba a punto de sucumbir al mar, pero con esta nueva fuerza el buque respondió una vez más.

¿Soportará Raymond?’

'No lo sé, nadie lo sabe. Si no lo logra, no hay nada más que hacer. Estamos cerca de la muerte y puede llegar en cualquier momento. Minnie, Minnie Fay, quiero decirte que te amo, y si esto significa vida o muerte mi amor es el mismo.' En respuesta ella puso su mano sobre la de él y se juntaron.

Por una hora estuvieron observando la vela y las cuerdas ya que si se rompían significaba la muerte. La vela se hinchaba hasta sus límites y a veces parecía romperse, pero logró mantenerse. A las dos de la mañana la luna salió y las nubes fueron desapareciendo poco a poco.

Media hora después el capitán llegó sonriendo al ver a los dos juntos y dijo: 'lo peor ya pasó.'

Cinco días después el Colón pasó frente a Narrows remolcado por un pequeño vapor. Era una bella mañana y la grama en Staten Island nunca se había visto más verde. Raymond y su prometida estaban juntos cuando pasaron por Fort Hamilton. 
¿Entonces será en cuanto oigas de tu padre?’ Dijo él.

'Sí'

'Minnie querida, tengo una confesión que hacer,' dijo un minuto después. 'Robé algo tuyo el día que zarpamos; lo recogí en la cubierta. ¡Mira!' Y sacó el objeto elástico de su bolsa.

Ella lo vio perpleja por un minuto; entonces su cara se puso roja y soltó una carcajada exclamando: 'Pero Raymond, esa es la liga de la tía. 'Tú deberías saber mejor.'

\section{Condiciones del sitio arqueológico}

"Por patrimonio cultural subacuático se entiende todos los restos de existencia humana que tengan un carácter cultural, histórico arqueológico, que hayan estado bajo el agua parcial o totalmente, de forma periódico o continua, por lo menos durante 100 años..." (Artículo 1 de la Convención del 2001, UNESCO). Desde una perspectiva más amplia y de mi preferencia está la siguiente definición: "Por patrimonio cultural subacuático se entiende todos los rastros de existencia humana incluyendo todo tipo de materiales culturales que hayan estado bajo el agua, parcial o totalmente, de forma periódica o continua y que puedan ser estudiados para conocer individuos y sociedades del pasado". Esta definición concuerda con la definición de arqueología y el alcance cronológico de este campo, también permite la protección de materiales culturales que tengan menos de cien años. El SS Colón se enmarca dentro de ambas definiciones.

El sitio arqueológico subacuático SS Colón se ubica en la playa de Acajutla, departamento de Sonsonate, a unos doscientos metros hacia el este de la bocana del rio Sensunapán (Figuras 3 y 4). Es muy fácil identificarlo ya que los restos sobresalen en la playa cerca del oleaje. Cuando la marea está baja, el agua del mar no hace contacto con los fragmentos, pero cuando la marea sube quedan cubiertos parcialmente. Los restos consisten en la parte superior del motor con los dos cilindros y otros segmentos no identificados que continúan hacia el norte cubiertos por la arena. Se desconoce las condiciones de las partes del barco que están cubiertas, pero todo indica que gran parte del motor se encuentra debajo de los cilindros. Tampoco se sabe si existen restos bajo el agua dentro del mar.

Considerando el tiempo que tiene de estar en este ambiente (108 años), los REVista DE MUSEOLOGÍA KÓOT, 2013, AÑO 3, No 4, ISSN 2078-0664, ISSNE 2307-3942 
fragmentos del motor están bien conservados y definidos. Esta es una cualidad en este tipo de hierro y una de las razones por las cuales estos motores eran construidos en las fábricas de Escocia, aunque el hecho que consumían menos carbón era otra ventaja. En la parte inferior se aprecia parte de las "patas" de hierro que estaban atornilladas al casco y que sostenía ambos cilindros en la parte superior. Los dos cilindros están sobre estas dos patas y en la parte superior se observan los dos espacios donde estaban los pistones. Aunque los pistones ya no existen se pueden observar los fragmentos de hierro que los sostenían en el interior de los cilindros.

Durante la visita al sitio entrevisté a un señor quien no quiso proporcionar su nombre y vive justo al lado norte de los restos frente a la playa. Este señor dijo que hace aproximadamente un año llegaron un grupo de hombres que trataron de fragmentar parte de los restos para venderlos como chatarra para posteriormente fundirlos. Esta depredación se ha vuelto una práctica común en otros sitios arqueológicos subacuáticos que son destruidos paulatinamente y vendidos por libra ${ }^{14}$. Los resultados de esta acción de saqueo son evidentes en la parte superior del cilindro este donde falta un fragmento de hierro. Afortunadamente y gracias al buen hierro escocés, los saqueadores se dieron por vencido cuando fue muy dificultoso extraer más pedazos del motor.

Nuestro patrimonio cultural subacuático se está perdiendo rápidamente. Es necesario tomar medidas concretas en la protección de este importante legado arqueológico.

\section{Referentes bibliogáficos}

Chandler Robert J. y Stephen J. Potash. Gold, Silk, Pioneers \& Mail. Pacific Maritime History Series. Number 6. Friends of The San Francisco Maritime Museum Library. San Francisco. 2007.

Delgado, James P. To California by Sea. A Maritime History of the California Gold Rush.

University of South Carolina Press. 1990

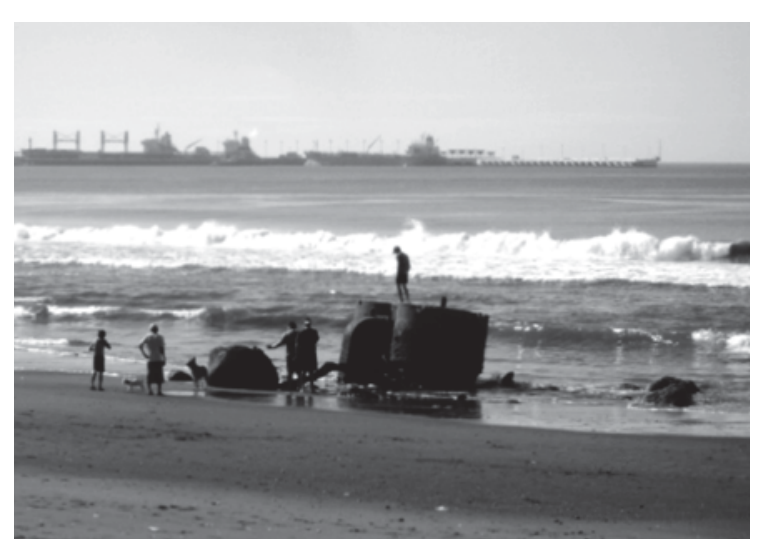

Figura 14. Restos del SS Colón con turistas

$\overline{\text { 14. Ibíd. Gallargo. } 2011 .}$ 


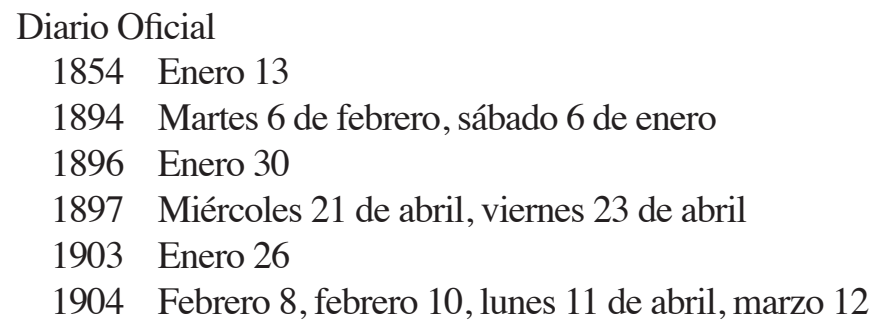

Gaceta del Salvador

1849 Mayo 25

Gallardo, Roberto. Delimitación de un área de protección para el pecio SS Douglas, Los Cóbanos, Sonsonate. El Salvador. Documento inédito en la Dirección de Arqueología en el Museo Nacional de Antropología Dr. David J. Guzmán. 2010.

Informe Visita y Registro del Sitio Arqueológico Subacuático SS San Blas. Playa San Blas, Departamento de La Libertad, El Salvador. Documento inédito en la Dirección de Arqueología en el Museo Nacional de Antropología Dr. David J. Guzmán. 2011.

Registro y documentación del pecio "SS San Blas". Playa San Blas, departamento de La Libertad, El Salvador. En Koot, revista de museología, Museo Universitario de Antropología. Universidad Tecnológica de El Salvador, Año 2, octubre de 2012, No. 3. San Salvador, El Salvador. 2012.

Lindo-Fuentes, Héctor. La Economía de El Salvador en el Siglo XIX. Biblioteca de Historia Salvadoreña. Dirección de Publicaciones e Impresos, CONCULTURA. 2002.

La Quincena. Revista. Septiembre 1 de 1904. San Salvador, El Salvador. 1904.

McCollough, David. The Path Between the Seas. The Creation of the Panamá Canal 1870 - 1914. Simon \& Schuster Paperbacks. Rockefeller Center, 1230 Ave. of the AmericasNew York, New Yor 10020. 1977.

Suárez, José Roberto. 1854 Barcos y Velas. Huellas Históricas Marítimas de El Salvador. Patrocinado por el Grupo Calvo. 2011.

\section{Artículos de periódicos.}


Daily Evening Bulletin

1872 Noviembre 17

1873 Marzo 11, mayo 12, agosto 19.

Hawaiian Gazette

1873 Abril 23, julio 25

Hilo Tribune

1904 Abril 22

Omaha Daily Bee

1874 Julio 15

1877 Abril 28

1898 Mayo 24

National Republican

1882 Mayo 31, julio 1

1883 Mayo 8, julio 9, agosto 8, sept. 10, oct. 9, nov. 5.

1884 Feb. 5, abril 28, mayo 31, sept. 20

New York Times

1886 Febrero 11.

1894 Oct. 30

New York Tribune

1907 Septiembre 29

North American and United States Gazette

1873 Enero 7.

Pittsburgh Dispatch

1889 Julio 26.

Sacramento daily-record union

1883 Mayo 5

1885 Junio 17

1890 Agosto 15 , sept. 15

Springfield globe-republic

1885 Julio 17. 
St. Paul Daily Globe 1885 Abril 11.

The Anaconda Standard

1891 Junio 28

The Atlanta Daily Sun

1873 Enero 8

The Bourbon News

1904 Abril 12, 15

The Columbus Journal

1882 Julio 12.

The Daily Morning Astorian

1889 Junio 21

1890 Sept. 14.

The Daily Phoenix

1874 Julio 28.

The Evening World

1887 Dic. 8.

1888 Mayo 24.

1889 Feb. 14.

The Globe-republican

1890 Sept. 17

The Hawaiian Gazette

1893 Julio 25

1901 Mayo 14, sept. 3

The Hawaiian Star

1901 Marzo 14, Julio 11, agosto 19

The Honolulu Republican

1901 Junio 26

The Iola Register

1885 Abril 3 
The Morning Call

1893 Agosto 20, 31

1894 Marzo 17

The Nebraska Advertiser

1903 Sept. 25

The New York Times

1898 Agosto 20

The North Platte semi weekly tribune

1895 Agosto 16

The Ruttland Daily Globe

1874 Feb. 5

1876 Agosto 28

The Salt Lake Herald

1880 Diciembre 24

1885 Abril 1

1891 Feb. 4

1898 Junio 18

The San Francisco Call

1895 Junio 13, agosto 15

1896 Julio 5, sept. 7, nov. 20

1897 Marzo 26, sept. 20, nov. 27

1900 Dic. 29

1901 Feb. 25, abril 25, junio 2, julio 31

1902 Mayo 15, julio 5, 3; sept. 2, sept. 28, nov. 4

1903 Enero 1, 12; mayo 6, 7; nov. 4,

1904 Enero 15, mayo 18, 19, 22; abril 13, 15, junio 7, Julio 10, 29; agosto 13

The Seattle Star

1902 Oct. 7

The St. Louis Republic

1903 Sept. 19

The Nebraska Advertiser

1903 Sept. 25 


\section{The Sun}

1879 Diciembre 21

1880 Junio 18

1881 Marzo 18

1883 Enero 10, abril 9, mayo 8, sept. 22

1884 Mayo 2

1885 Agosto 21

1889 Mayo 19, junio 21, dic. 17

1890 Agosto 14 , dic. 18

1891 Febrero 16, abril 20, junio 20, sept. 27, oct. 27

1887 Febrero 7, marzo 10, abril 10, mayo 13, junio 9, oct. 10, nov. 10, dic. 6

1888 Enero 9, feb. 9, mayo 6, julio 16, sept. 20, dic. 19

The Times

1898 Marzo 4

The Times Dispatch

1904 Abril 13, marzo 4

The Tombstone

1885 Agosto 26

The Wichita Daily Eagle

1891 Dic. 5

Vermont Phoenix

1885 mayo 22 


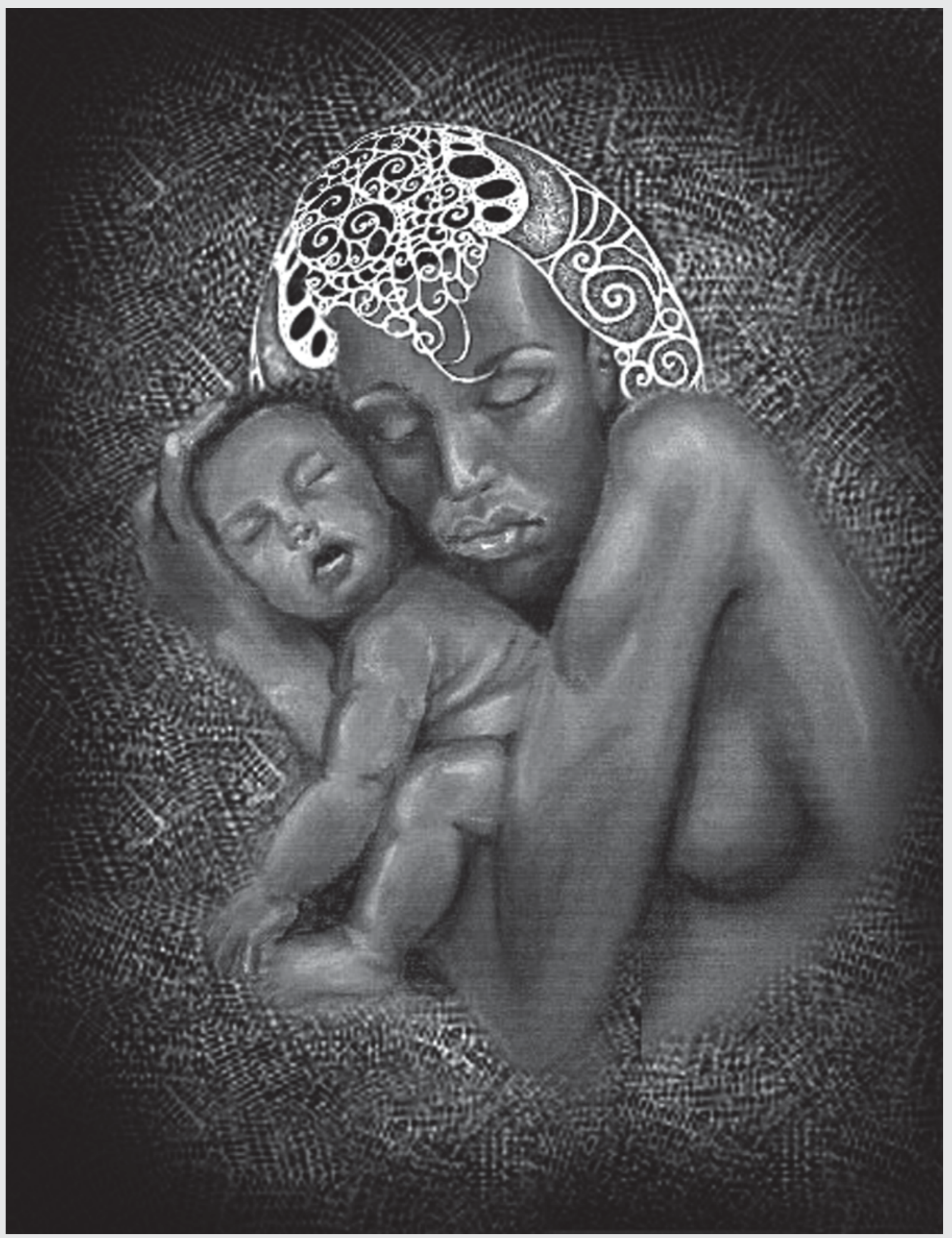

Amor Incondicional. Técnica mixta, 8.5” x 11”. Rita Araujo. 2012. 